\title{
Article
}

\section{Morphology and Genesis of Ballas and Ballas-Like Diamonds}

\author{
Anton Pavlushin ${ }^{1,2, *}$, Dmitry Zedgenizov ${ }^{1,3} \mathbb{D}^{\mathbb{D}}$, Evgeny Vasil'ev ${ }^{4}$ and Konstantin Kuper ${ }^{5}$ \\ 1 Department of Geology and Geophysics, Novosibirsk State University, 630090 Novosibirsk, Russia; \\ zed@igm.nsc.ru \\ 2 Diamond and Precious Metal Geology Institute, Siberian Branch, Russian Academy of Sciences, \\ 677000 Yakutsk, Russia \\ 3 V. S. Sobolev Institute of Geology and Mineralogy, Siberian Branch Russian Academy of Sciences, \\ 630090 Novosibirsk, Russia \\ 4 Saint-Petersburg Mining University, 199106 Saint-Petersburg, Russia; simphy12@mail.ru \\ 5 Budker Institute of Nuclear Physics, Siberian Branch Russian Academy of Sciences, \\ 630090 Novosibirsk, Russia; k.e.kuper@inp.nsk.su \\ * Correspondence: pavlushin@diamond.ysn.ru; Tel.: +7-924-662-02-07
}

\section{check for}

updates

Citation: Pavlushin, A.; Zedgenizov, D.; Vasil'ev, E.; Kuper, K. Morphology and Genesis of Ballas and Ballas-Like Diamonds. Crystals 2021, 11, 17. https://dx.doi.org/10.3390/ cryst11010017

Received: 22 November 2020 Accepted: 24 December 2020 Published: 27 December 2020

Publisher's Note: MDPI stays neutral with regard to jurisdictional claims in published maps and institutional affiliations.

Copyright: (c) 2020 by the authors. Licensee MDPI, Basel, Switzerland. This article is an open access article distributed under the terms and conditions of the Creative Commons Attribution (CC BY) license (https: / / creativecommons.org / licenses/by/4.0/).
Abstract: Ballas diamond is a rare form of the polycrystalline radial aggregate of diamonds with diverse internal structures. The morphological features of ballas diamonds have experienced repeated revision. The need that this paper presents for development of a crystal-genetic classification was determined by a rich variety of combined and transitional forms of ballas-like diamonds, which include aggregates, crystals, and intergrowths. The new crystal-genetic classification combines already-known and new morphological types of ballas as well as ballas-like diamonds discovered in the placers of Yakutia, the Urals, and Brazil. The ballas-like diamond forms include spherocrystals, aggregates with a single crystal core, split crystals, radial multiple twin intergrowths, and globular crystals. The crystal genetic scheme of the evolution of ballas and ballas-like diamonds is a sequence of the morphological types arranged in accordance with the conventional model of the dependence of the mechanism and diamond growth from carbon supersaturation developed by I. Sunagawa. The evolution of the growth forms of ballas and ballas-like diamonds was tracked based on the macrozonal structure of diamonds varying from a flat-faced octahedron to a fibrous cuboid with its transition forms to the radiating crystal aggregates. The morphological diversity of the ballas-like diamonds depends on the level of supersaturation, and abrupt changes of the level of supersaturation engender abrupt changes in a mechanism of crystal growth. The change in the rate of growth under the influence of adsorption and absorption of the mechanic impurities accompanied the sudden appearance of the autodeformation defects in the form of splitting and multiple radial twinning of crystals. The spherical shape of Yakutia ballas-like diamonds is due to the volumetric dissolution that results in the curved-face crystals of the "Urals" or "Brazilian" type associated with ballas diamonds in placers.

Keywords: ballas diamond; ballas-like diamond; twinning; morphology; polycrystalline of diamonds; crystals splitting

\section{Introduction}

Ballas diamond is a rare type of natural diamond aggregate that A.F. Williams [1] first described as "shot bort", a term that emphasised the similarity of the globular shape and dark grey colour of ballas diamonds. Later, Yu.L. Orlov [2,3] defined ballas diamonds as spherulites with a radial-fibrous structure. Ballas diamonds are well known in the placers of Brazil and South Africa [1,3-5], while location of ballas in Russia is rare and has to date received little attention in systematic studies. The classic ballas diamonds are absent in kimberlites and have been reliably established in the diamondiferous placers of the Urals [3,6], the Sayan region [7,8], and Yakutia [9]. Ballas-like spherical intergrowths 
of crystals in the Sytykanskaya and Yubileinaya kimberlite (Yakutia kimberlite province) pipes have been described [10].

In addition to the rare ideal spherical shape of spherulite characteristic of classical ballas diamonds, many ballas-like forms have been found among natural diamonds, and the term "ballas-like diamond" has become firmly established in the literature. The term "ballas-like diamond" was used to describe natural spherocrystals [10-12], complex twin aggregates [10], polycrystalline coats, and shells with a radially oriented structure of fibrous aggregate on a single crystal core $[10,13,14]$. The similarity of the mosaic diamonds intergrowths with the radial structure with ballas diamonds was emphasised in [15-18]. The listed types of diamonds are not included in conventional Orlov's mineralogical classifications [2,3]; it was considered instead as separate morphological types of diamonds; the common features are the spherical shape and radially oriented crystallites. The literature $[5,12,14,19,20]$ has extensively discussed the problem of differentiating ballas-like diamonds from ballas diamonds, as well as refinement of the morphological and genetic features of ballas-like diamonds, but has yet to reach a conclusion. A wide variety of morphological types was observed in the synthetic ballas diamonds synthesised in various conditions [13,14,19-24]. The main aim of this work was to study the unusual types of ballas and ballas-like diamonds from various regions by means of complex minerals methods to establish the diversity of morphological types and to determine the genetic features of the formation of ballas and ballas-like diamonds.

\section{Materials and Methods}

We considered samples of ballas and ballas-like diamonds from the deposits of Yakutia, the Urals and Brazil. Ballases from Brazil [5] and the Urals [2,6] are classical examples in the studies of ballas diamond structure. The Urals ballases formed the basis for the Yu.L. Orlov [3] mineralogical classification of diamonds and can be used as reference samples for comparative analysis. The stone from Brazil $(0.95 \mathrm{ct})$ was found in an alluvial deposit of Macaúba river in Minas Gerais state. The ballas from the Urals $(10.09 \mathrm{ct})$ was mined in a placer of Vijay river. Ballas-like diamonds weigh from 3.11 to 3.45 , and were mined in the Holomolooh placer in Anabar district, Russia.

Optical microscopy studies of the morphology of diamonds were performed by means of Olympus SZX-12 stereoscopic microscope (Olympus Corp., Tokyo, Japan) equipped with digital camera. An OI-19 ultraviolet illuminator (Lomo Ltd., St.-Petersburg, Russia) was used to excite photoluminescence. The micromorphology of the surface and the internal structure of diamonds were investigated by means of a Jeol JSM-6480LV scanning electron microscope (Jeol Ltd., Tokyo, Japan) at an accelerating voltage of $20 \mathrm{kV}$ (DPMGI SB RAS, Yakutsk). Cathodoluminescence patterns were recorded with a Gatan Mini CL attachment to the Jeol JSM-6480LV electron microscope (Jeol Ltd., Tokyo, Japan) and a Centaurus attachment to a Leo-1430V electron microscope (IGM SB RAS, Novosibirsk).

Goniometric measurements were performed on a ZRG-3 goniometer (Heidelberg University, Heidelberg, Germany) (accuracy from 2' to 20'). Diamond crystals were adjusted based on signals from faces (111) located in the same zone [101].

Polished oriented sections of diamonds were studied by means of electron backscatter diffraction (EBSD) analysis to establish the orientation of crystallites in deformed crystals, aggregates, and twin crystal intergrowths. A Hitachi S-3400N scanning electron microscope (Hitachi Ltd., Tokyo, Japan) equipped with an Oxford Instruments HKL detector was used. The texture analysis of the crystal blocks, the angles of their orientation and the statistical characteristics of the positions of grains with a certain orientational angle in the sample were determined. The accuracy of the orientation angles determination was $0.5^{\circ}-1.0^{\circ}$.

The X-Ray diffraction Topography (XRDT) method was realized at «Microscopy and tomography» synchrotron radiation (SR) beamline station of the VEPP-3 synchrotron source [25]. The energy of photons of X-ray monochromatic beams used in XRDT was $11 \mathrm{keV}$. Slits installed upstream the sample formed $2 \times 2 \mathrm{~mm}^{2}$ collimated X-ray beam. The sample was placed at a distance of $16.5 \mathrm{~m}$ from SR source. To find the Bragg reflection, 
the investigated crystal slab was pre-aligned in a translated axis with an accuracy of $1 \mu \mathrm{m}$ and in a rotation axis with an accuracy of 0.001 . In order to efficiently surpass the spatial resolution of the detector, a magnification system was used. Two asymmetrically cut crystals reflecting in mutually perpendicular directions gave a uniform two-dimension magnification of a factor of 20 in registered images.

\section{Results}

\subsection{Morphology and Internal Structure of Ballas and Ballas-Like Diamonds}

3.1.1. The Urals Ballas Diamond

The diamond (UR) is large (Figure 1a), with a diameter of $1.5 \mathrm{~cm}$ and a weight of 10.09 carats. The surface of the diamond has a specific relief characteristic of classical ballas diamonds [3]: it is unevenly covered with irregularities, depressions, and microfaces; the surface of the ballas is translucent and has a yellowish-grey colour; and some areas are transparent and exhibit a grey colour as well. On the surface of the cut passing through the centre of the ball, a transparent colourless core with uneven outlines of the boundaries is observed (Figure 2a). The core is outlined by a clearly distinguishable radial-fibrous aggregate of crystallites, which increase in size from the centre to the periphery and form two circular zones in the radial aggregate that consist of thin needle-like and then larger transparent crystallites (Figure 2a-c). The boundary between the outer and inner zones is marked with dark brown spots of iron hydroxides (Figure 2a). The photoluminescence of the ballas diamond corresponds to its macrozonal structure (Figure 2b). The transparent areas of the ballas diamond glow zonally in bright blue and light blue, forming several radial rays. Near the surface, an aggregate of crystallites exhibits a zonal glow of green and bright green colours (Figure $2 b$ ).
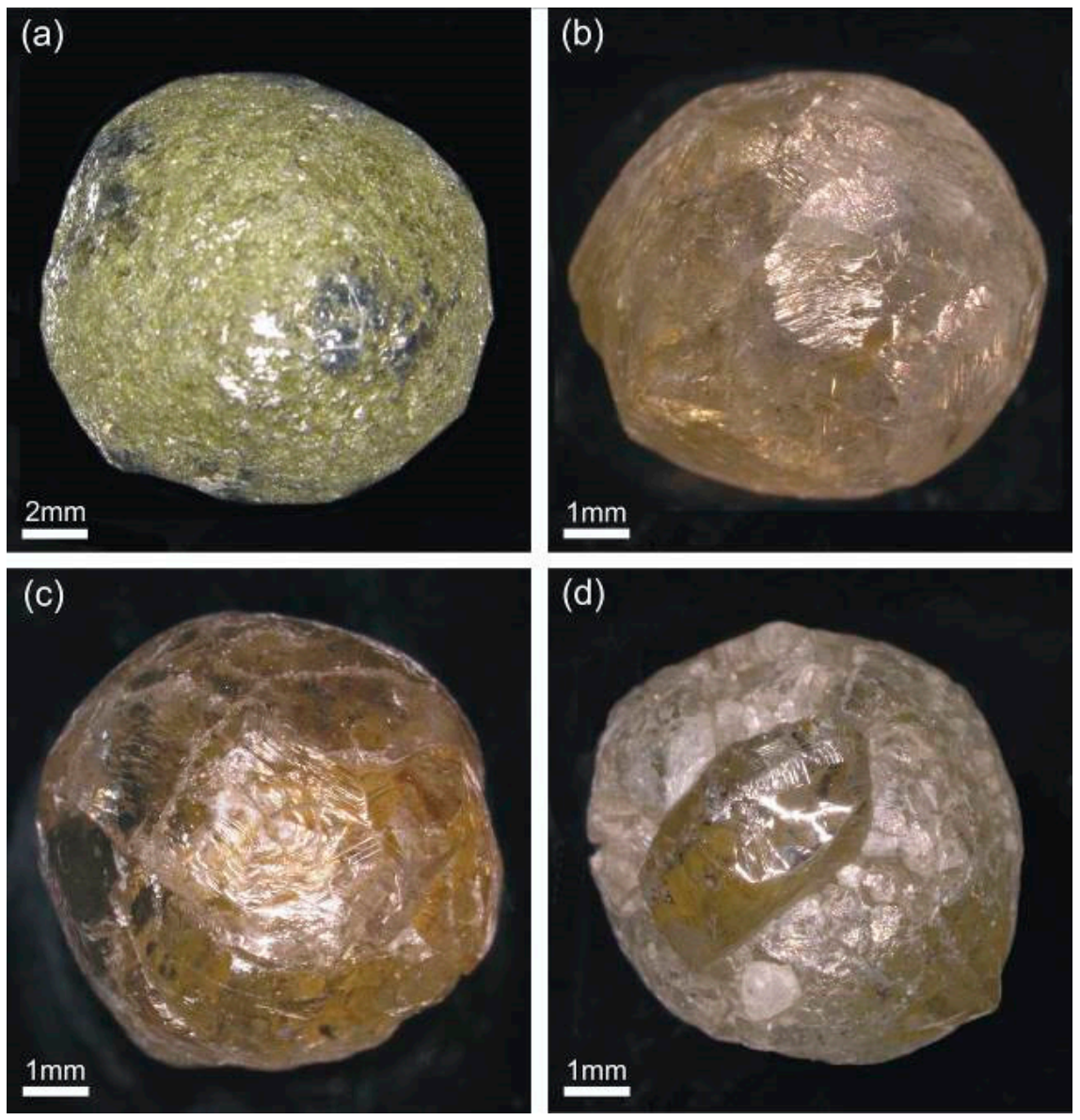

Figure 1. Ballas and ballas-like diamonds from the Urals (a) and Yakutia (b-d). 

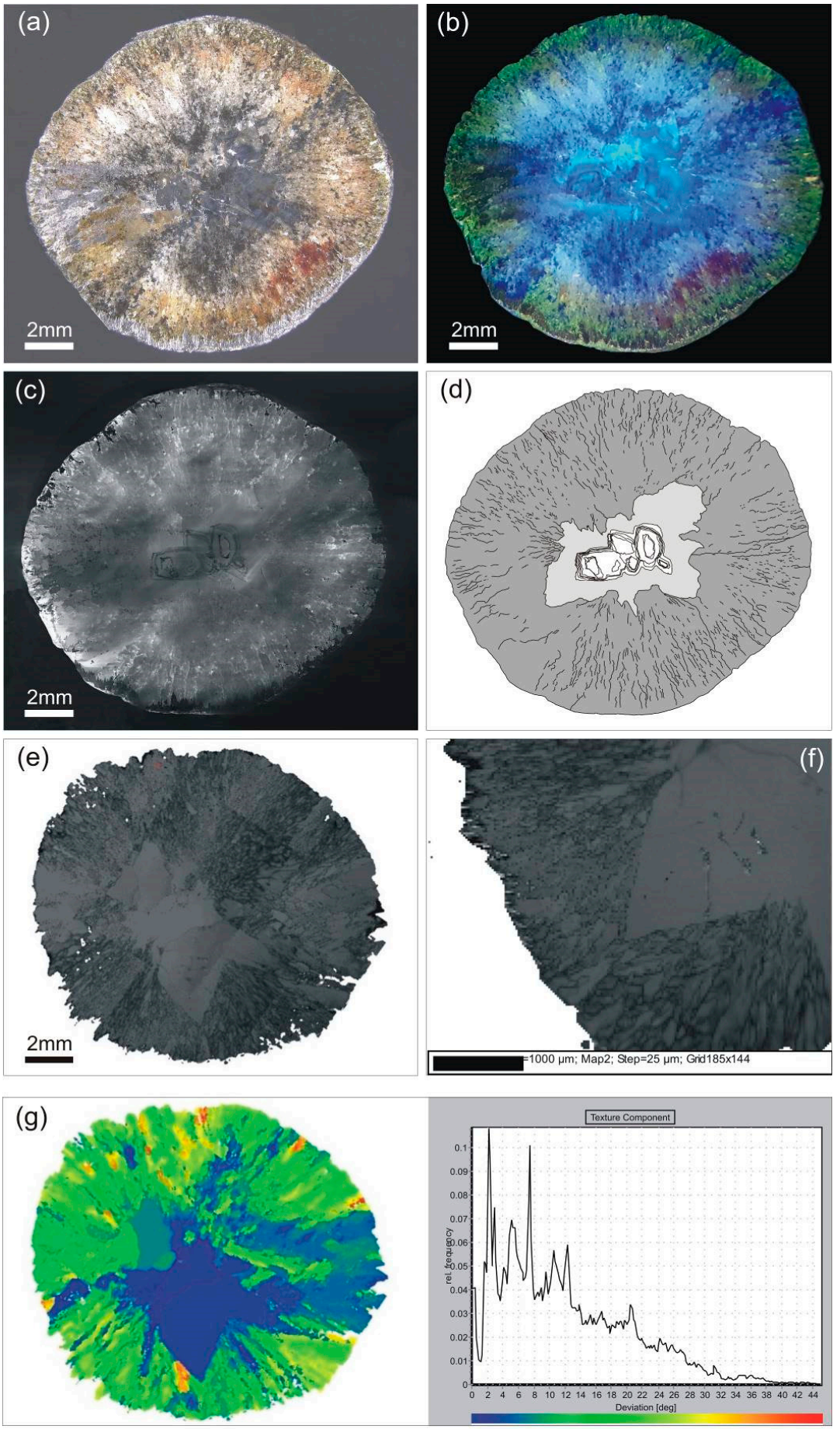

Figure 2. Central plate of Urals ballas diamond: (a) transmitted light image; (b) UV-light image; (c) CL image; (d) Scheme of the internal structure; (e,f) reflected light; (g) electron backscatter diffraction (EBSD) image and texture component diagram.

Cathodoluminescence of the surface of the central plate of the ballas revealed fine details of its structure in the best way (Figure 2c). Several microcrystals of diamond in close intergrowth with each other are observed in the central part of the ballas (Figure 2d, highlighted in white area). A shapeless diamond shard was found in the centre of growth of each microcrystal. Microcrystals are outlined by a thin octahedral zone, the lines of which intersect with each other and then coat several crystal cores together. Towards the periphery, the aggregate of crystals, which apparently passed the stage of geometric selection, is replaced by a full-faceted area without any signs of zoning (Figure $2 \mathrm{~d}$, highlighted in 
light gray). The full-facet region is gradually transformed into a radial-fibrous aggregate (Figure 2d, highlighted in dark gray).

The images of the central section of the Urals ballas diamond, obtained by means of X-ray topography (Figure 2e,f) and EBSD (Figure 2g) method, clearly show the structure of its single-crystal and polycrystalline regions (Figure 2e,f). The centre of the ballas diamond is composed of several slightly misoriented (from $2^{\circ}-4^{\circ}$ to $10^{\circ}$ ) crystalline blocks that enclose the zonal and full-faceted regions of the ballas diamond. The blocks have a delta shape, elongated radially from the centre of the aggregate (Figure $2 \mathrm{e}-\mathrm{g}$ ), and transform into split sheaf-like bundles that consist of small misoriented (from $8^{\circ}$ to $22^{\circ}$ ) crystallites (Figure 2e,f). The secondary-size bunches of rays of fibrous crystallites originating in the re-entrant corners between delta-shaped blocks show a misorientation from $5^{\circ}$ to $6^{\circ}$. Some bunches of crystallites located at the boundaries between large adjacent bunches show a more significant misorientation that ranges from $30^{\circ}$ to $38^{\circ}$. The most frequent misorientation values of the crystallites in the aggregate are $2^{\circ}$ and $7^{\circ}$ (Figure $2 \mathrm{~g}$ ). In general, sheaf-like aggregates constitute the entire spherulite of the ballas diamond.

\subsubsection{Ballas and Ballas-Like Diamonds from the Yakutia}

This group of diamonds is represented by three large specimens of regular spherical shape (Figure 1b-d). The diamonds are fractured, transparent, and in places translucent, their color is heterogeneous, light gray and yellowish gray. Areas filled with inclusions are dark gray in color.

Yakutia ballas-like diamond (RB-2). Visually, the diamond has a spherical, weakly expressed crystallographic shape (Figure 1b). The surface of RB-2 is uneven and is covered with a system of parallel oriented furrows. The weight of the diamond is $3.45 \mathrm{ct}$, and the diameter is $9.5 \mathrm{~mm}$.

The external shape of the spherical diamond has a well-defined tetrahedral appearance in the SEM image (Figure 3a,b). The hemihedria of the crystal is indicated by the faces of the octahedra unevenly developed along the tetrahedral motif. Conventionally, the large, hexagonal, better-developed faces of the octahedron correspond to the "positive tetrahedron", and the less-developed triangular faces of the octahedron, which almost disappeared from the faceting, correspond to the "negative tetrahedron". There are deep negative trigons and, more rarely, hexagonal etch pits on both types of faces of the octahedron (Figure 3), and these features indicate significant dissolution of the diamond crystal.

Another feature of a spherical crystal is the presence of an extended system of indexed micro faces (411), (311), (211), (100) zones on its surface. According to the interruption of light reflexes in the goniometer, the micro faces are separated from each other by stepped shading (Figure 3a-d), encircle the entire crystal, and are located between the welldeveloped faces of the octahedron, conventionally belonging to the "positive tetrahedron". As shown in the diagram (Figure 3b), the micro faces correspond to the crystallographic position of the edges of the "tetrahedron", which once again emphasises the tetrahedral outlook of the spherical crystal.

The zonal structure of the crystal is clearly visible in the central section (Figure 4a). The anomalously anisotropic outer zone, saturated with micro inclusions, is separated from the octahedral diamond core by cleavage cracks along (111) (Figure 4b). Their appearance is due to the relaxation of elastic stresses associated with the heterometry of the diamond crystal lattice at the interface between the crystal core and its outer zone.

Rectilinear zoning in the octahedral core is replaced by zigzag zoning in the outer zone of the crystal on the CL-images (Figure 4c). Its origin is probably associated with the multi-headed polycentric growth of the octahedron faces. According to the presence of a high concentration of micro inclusions in this zone (Figure 4a), it is associated with the decay of the growth front of the octahedral face into many crystallisation centres. The absorption of mechanical micro impurities by the crystal prevented flat-faceted growth of its octahedral layers. 

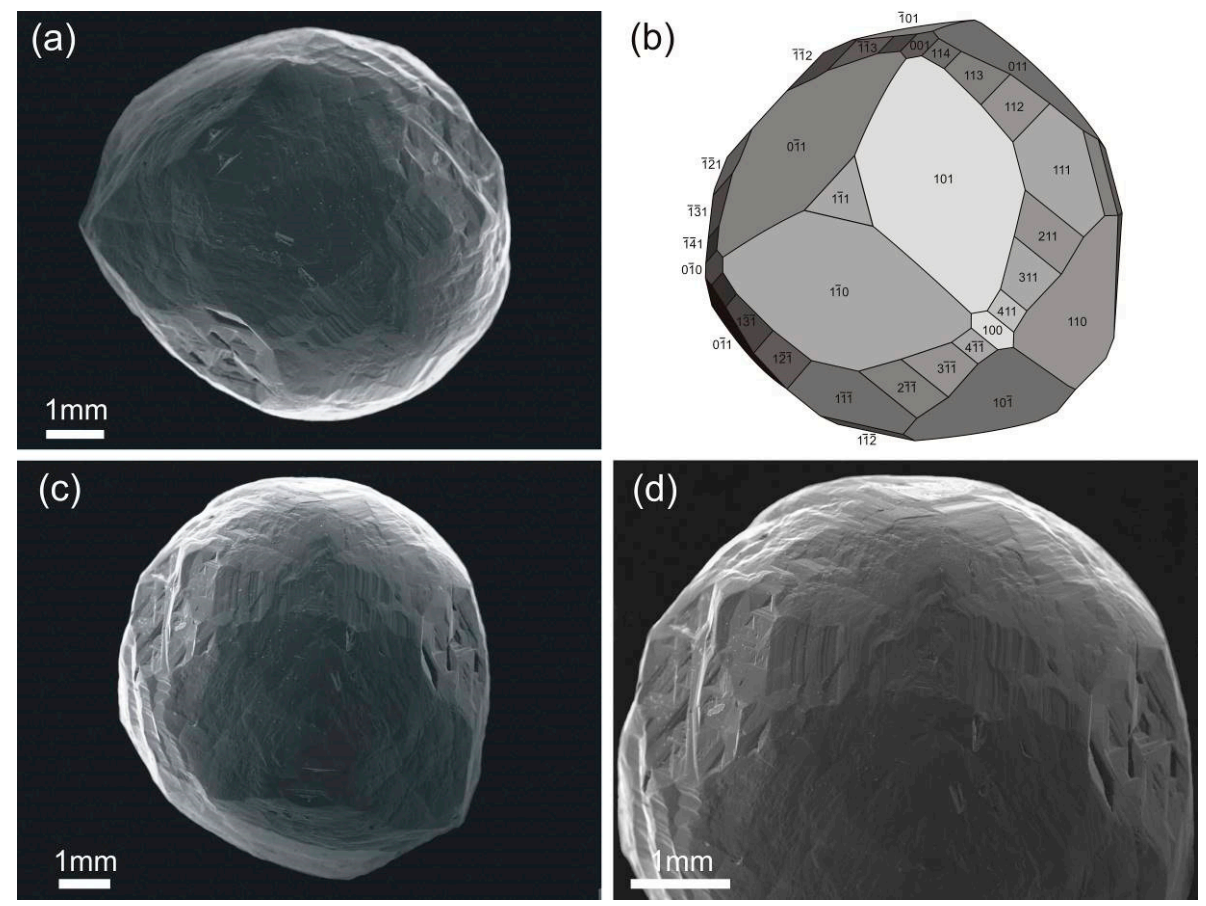

Figure 3. Morphology of Yakutia ballas-like diamond crystal (RB-2): (a,c,d) SEM images; (b) Crystallographic idealized model of the diamond.
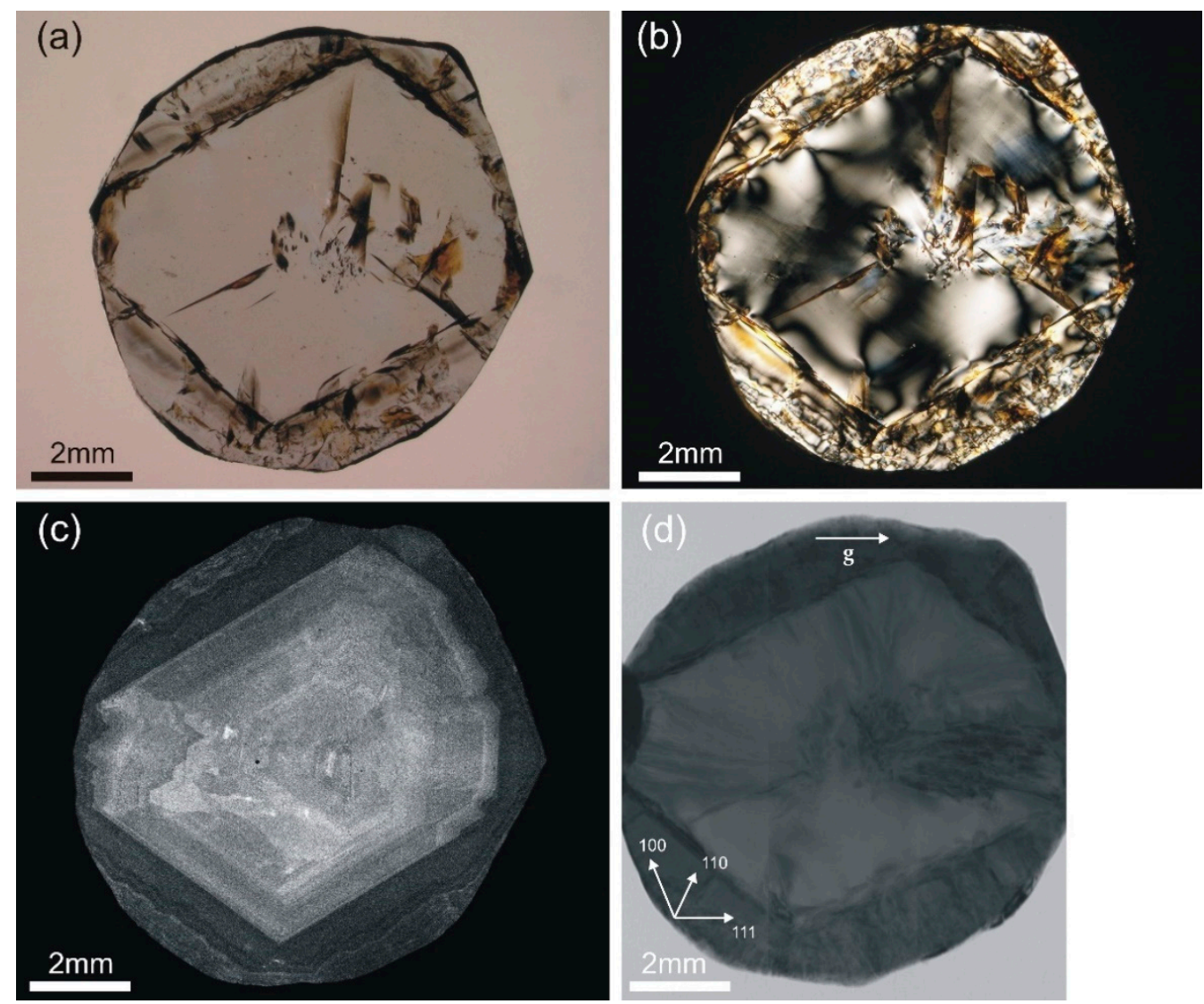

Figure 4. Central plate of ballas-like diamond RB-2: (a) Transmitted light image; (b) Polarized light image; (c) CL image; (d) X-ray topography image. 
X-ray topography of the plate shows (Figure 4d) that structural defects are distributed in the crystal according to the crystal's zoning and elastic stresses. Dislocation defects form radial bunches in the crystal, and the concentration of defects increases throughout the outer zone of the crystal.

Yakutia ballas (RB-4). The diamond is fractured, has a regular spherical shape, and exhibits an intense and luminescent blue colour. Its diameter is $7.2 \mathrm{~mm}$, and its weight is $3.11 \mathrm{ct}$.

The diamond has a smoothed surface that is dissected by extended etching channels. The dissolution of the diamond is also evidenced by rare reverse-oriented triangular etching pits on the relict faces of the octahedron.

Signs of regular accretion of diamond crystals that constitute the spherical diamond are revealed in observation of the crystallographic orientation of a system of hatching lines and a stepped relief of its surface (Figure 5a). Obviously, the shading is parallel to the edges of the octahedra of the cyclic twin of diamond crystals, and it is highlighted with red lines in the image retouching (Figure 5b) and is shown with black lines in the diagram of the structure of the twin intergrowth (Figure $5 \mathrm{c}$ ). Twin seams between octahedral crystals appear well on the dissolved surface of the spherical diamond and are shown with red dashed lines in Figure 5b and with solid red lines in Figure 5c,d.
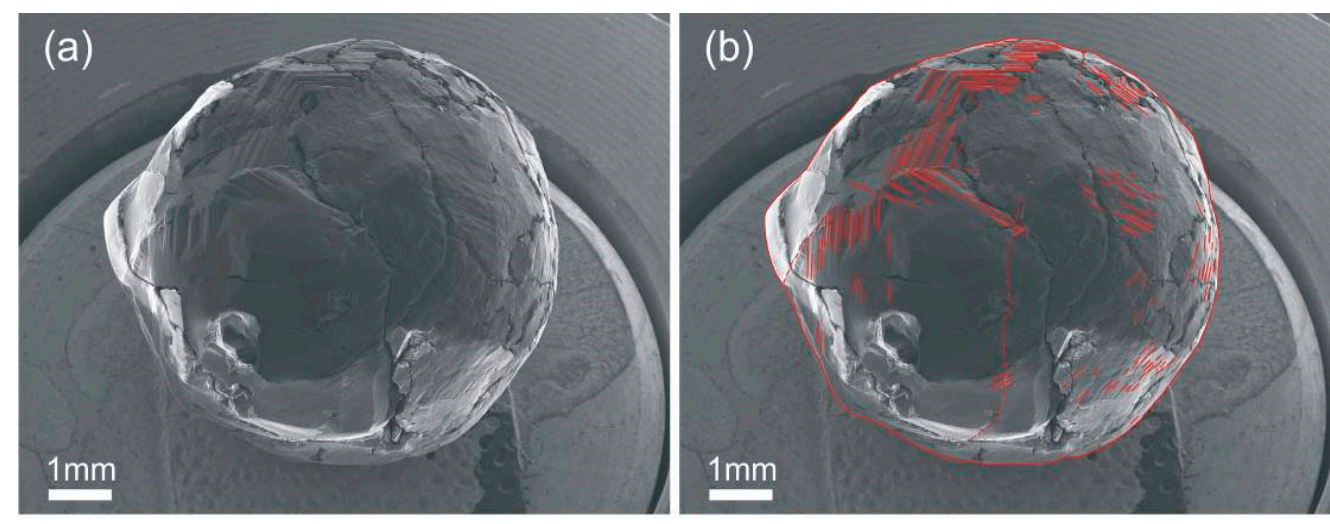

(c)
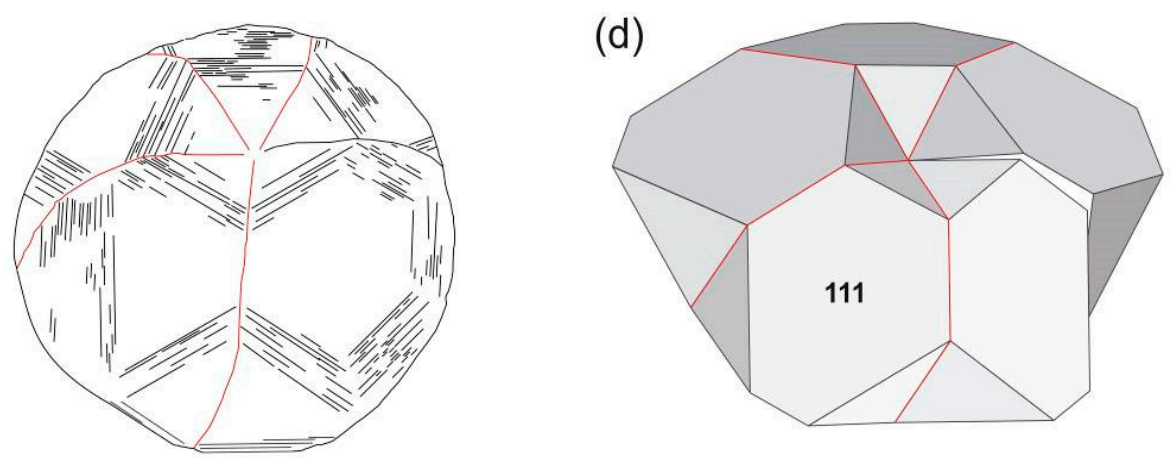

Figure 5. Morphology of the cyclic twin of ballas-like diamond crystal RB-4: (a,b) SEM image of the diamond and its retouched image; (c,d) Idealized model of the cyclic twin consisting out of five octahedral crystals.

Cyclic twins of octahedral diamond crystals sequentially intergrown are well known. Sometimes, these twins consist of five individuals that form a single open ring. Due to geometry restrictions, this ring cannot be completely closed because the octahedra that are intergrown in the twinning plane (111) physically cannot fill the entire space of a ring assembled from five octahedra without a gap [4]. The open space of the cyclic twin is also observed on the considered intergrowth; in its place, a deep crevice remained between octahedral individuals (Figure 5a). A characteristic pentagonal faceted rosette, consisting 
of many stepped micro faces (111), crowns the entire twin structure. On the reverse side, the diamond has a bumpy surface covered with etching channels.

The spherical cyclic twin was cut with the intersection of several twin boundaries found on the surface of the diamond. In the CL image (Figure 6a), re-entrant angles and a mirror-symmetric pattern of zoning lines marking twinning planes are clearly visible. Their directions are shown by red arrows in Figure $6 \mathrm{a}$ and again in Figure $6 \mathrm{c}, \mathrm{d}$. The rest of the diamond section is occupied by concentric wavy zoning, which is manifested in a segment composed of crystallites of a radial-fibrous aggregate (Figure $6 a, b)$. Zoning lines in twinned crystalline blocks and concentric zoning in the radial-fibrous aggregate form a single entity, which implies synchronous development from a single growth centre.
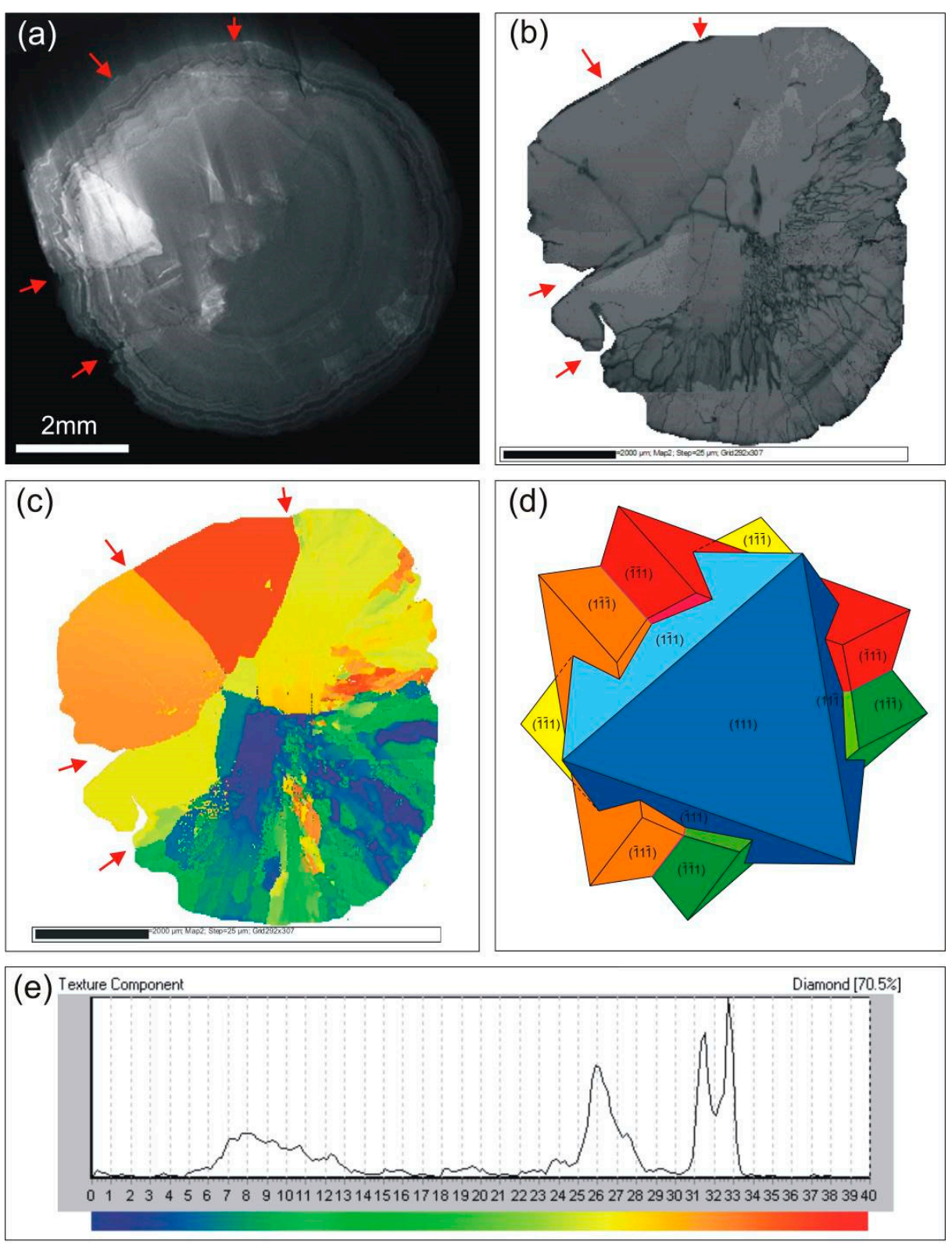

Figure 6. Polished central cut of ballas-like diamond RB-4: (a) CL image; (b) Reflected light; (c) EBSD image; (d) Interpretation of the multiple twining of crystals along (111); (e) Texture component diagram. The twin boundaries are marked in $(\mathbf{a}-\mathbf{c})$ with red arrows.

X-ray topography (Figure 6b) and EBSD analysis (Figure 6c) of the cut of the intersecting twinned crystal blocks were performed. The twin boundaries are marked in Figure $6 \mathrm{~b}, \mathrm{c}$ with red arrows. Crystalline blocks show significant misorientation with maxima 
at $0^{\circ}, 18^{\circ}, 26^{\circ}, 31.5^{\circ}, 38^{\circ}$ (Figure $6 \mathrm{e}$ ). It is noteworthy that the orientation of some of the crystallites in the radial-fibrous aggregate and twinned crystal blocks coincides in position and has a deviation of $0^{\circ}, 18^{\circ}, 26^{\circ}, 31.5^{\circ}$. It follows from the EBSD pattern analysis that twin intergrowths of diamond crystals originated in the centre of growth of a radial-fibrous aggregate and developed simultaneously with all its constituent rays. A model in the form of five twinned octahedral individuals with a radial orientation of twinning planes demonstrates their position in the ballas-shaped diamond aggregate (Figure 6d). The twin components shown in the graphical model (Figure $6 \mathrm{~d}$ ) are coloured to match the colours of the crystal blocks depicted in the EBSD image (Figure 6c). Thus, this ballas sample has a combined structure of a radial-fibrous aggregate and cycle twinned crystals.

Yakutia ballas (RB-5). The diamond has a regular spherical shape. Its diameter is $9.8 \mathrm{~mm}$, and its weight is $3.43 \mathrm{ct}$.

The specimen is a combination of radial-fibrous aggregate of crystallites and relatively large twinned crystalline blocks of diamond (Figure 1d). The areas of the ballas surface with signs of a radial structure (Figure 7a,b) consist of regions separated from each other by deep channels. They represent the butts of crystalline rays that are terminated by the flat (111) octahedron faces. Radial structure is revealed at the surface of the split made through the centre of the aggregate (Figure 7c). An inhomogeneous intense glow of bright blue colour in UV light emphasises the radial position of the crystal rays (Figure 7d).
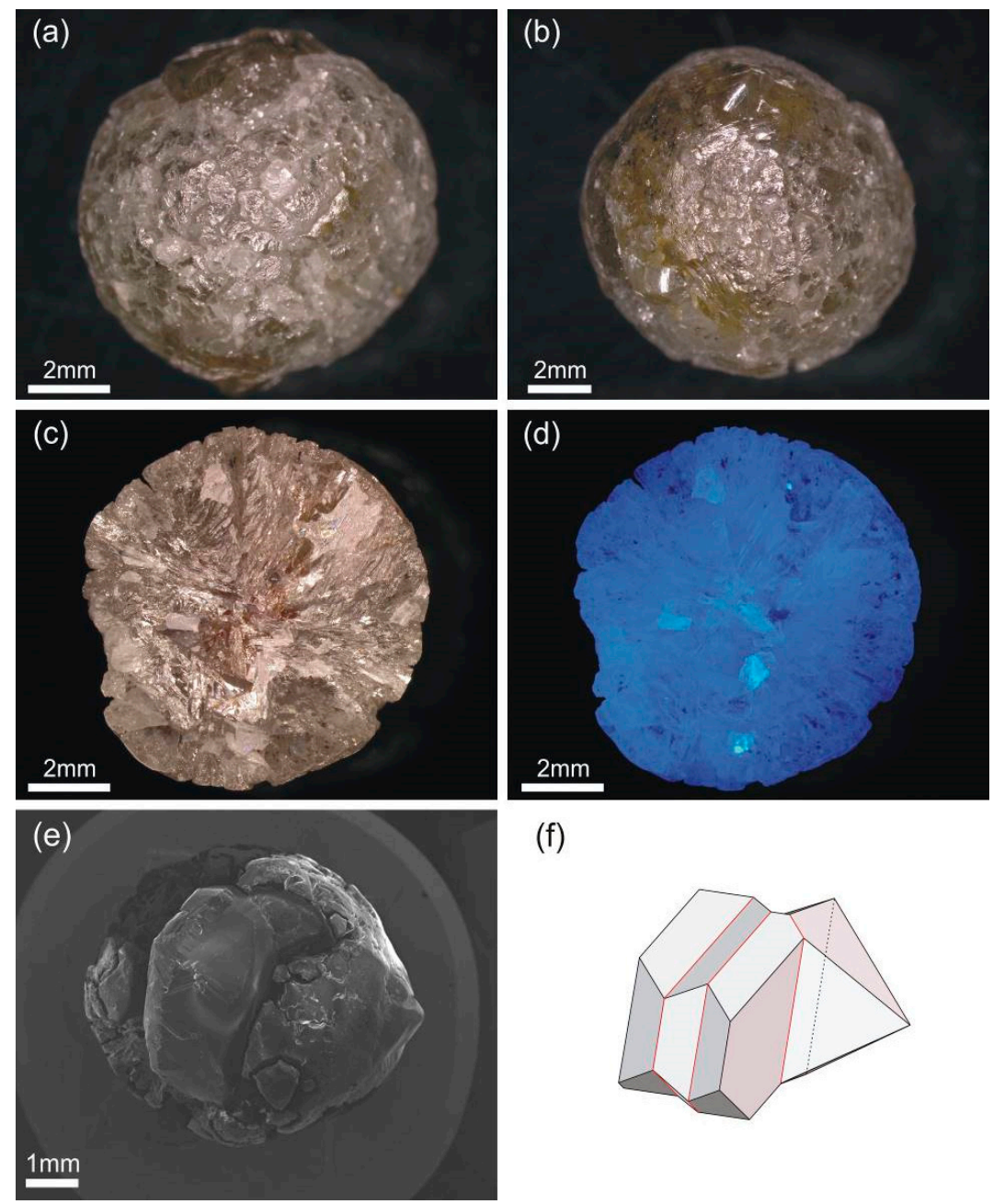

(f)

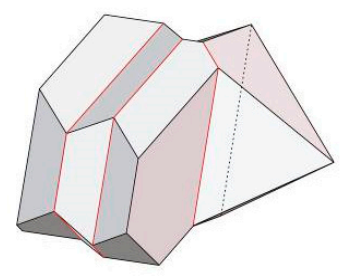

Figure 7. Morphology of Yakutia ballas RB-5 and crystallographic interpretation of its anatomy: (a,b) General view; (c) Fracture surface; (d) Image of PL under UV-light; (f) Model of the polysynthetic and spinal twins of octahedral crystals, twin planes (111) are highlighted with red color. 
There are three vertexes of one octahedral diamond crystal (Figures $1 \mathrm{~d}$ and $7 \mathrm{~b}$ ) on the surface of the ballas. Figure $7 \mathrm{~b}$ clearly shows that the octahedral face connecting its vertices has split into several segments. In addition, another large twinned crystalline block of diamond protrudes above the surface of the aggregate (Figures $1 \mathrm{~d}$ and 7e). It is a three-component polysynthetic twin, which is also in a twinning relationship along (111) with a large octahedral crystal noted above. A volumetric model of the twinned complex of a radial-fibrous aggregate constituting the framework (Figure 7f) with a single growth centre has been constructed.

\subsubsection{The Brazilian Ballas Diamond}

Brazilian ballas diamond (BR-3). The diamond has an elongated spherical shape and was originally defined as a ballas (Figure 8a). The colour of the diamond is yellowishgrey, the diamond is translucent, and its weight is $0.95 \mathrm{ct}$. The surface of the diamond is covered with numerous cavities, cracks, and chips. Scanning electron microscopy revealed the crystallographic shape of the diamond in the form of a highly corroded rounded hexahedroid with convex, irregular faces and indistinct edges (Figure 8b). Several tetragonal fragments of etching figures were found on the crystal surface, which enables recognition of significantly dissolved cube faces in them (Figure 8b).
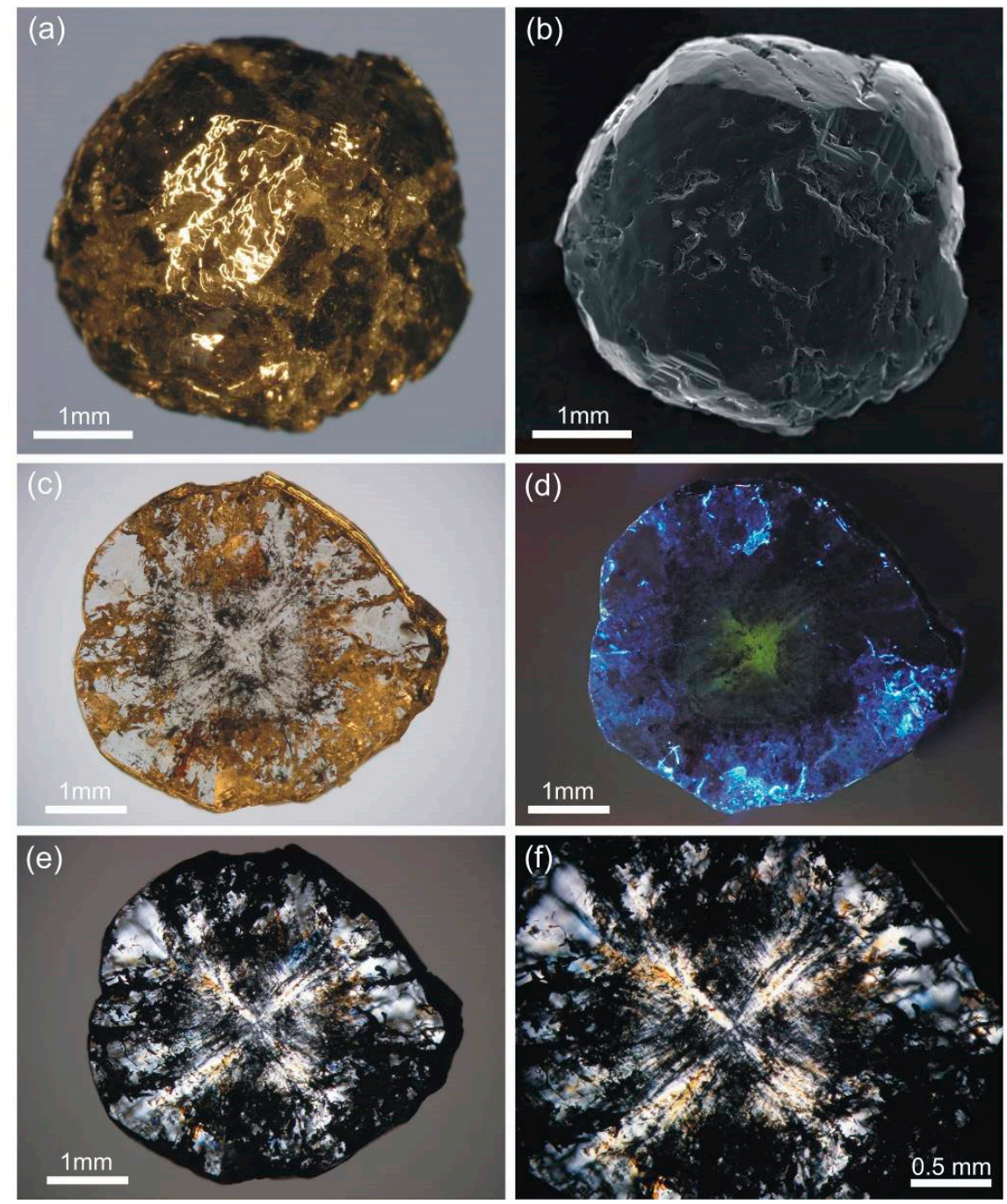

Figure 8. Morphology of the Brazilian diamond: (a) General view; (b) SEM image; (c) Transmitted light image of central plate; (d) Photoluminescence image; (e,f) Polarized light image. 
A central double side polished plate inclined to the (100) plane was made. Black inclusions fill the cubic central region of the diamond and mark sectors with growth pyramids of $<100>$ faces (Figure $8 \mathrm{c}$ ) in transmitted light. The photoluminescence also clearly shows zonal-sectorial glow (Figure $8 \mathrm{~d}$ ). The anomalous anisotropy reflections are sectorially distributed in the crystal in the polarised light (Figure 8e-f). Lines of optical stress in sectors $\langle 110\rangle$ extend from the centre to the periphery of the crystal, which allows us to speak of a single-crystal structure of diamond in the direction of the cube edges.

According to the CL image, the diamond consists of many radially oriented crystalline subindividuals separated from each other by microcracks and intergrowth boundaries. They exhibit a fine octahedral zoning, which reflects the growth trajectories of the vertices of the set of crystallites that compose the outer region of the diamond (Figure 9a-d). Subindividuals gradually increase in size. The tops of some of them, crossed by adjacent subindividuals, either stopped in development or changed the direction of growth (Figure $9 \mathrm{~d}$ ). The image of octahedral subindividuals growing on a cubic face composed of individual crystallites resembles a druse with a predominantly radial direction of crystal growth and displays phenomena of geometric selection (Figure 9d).
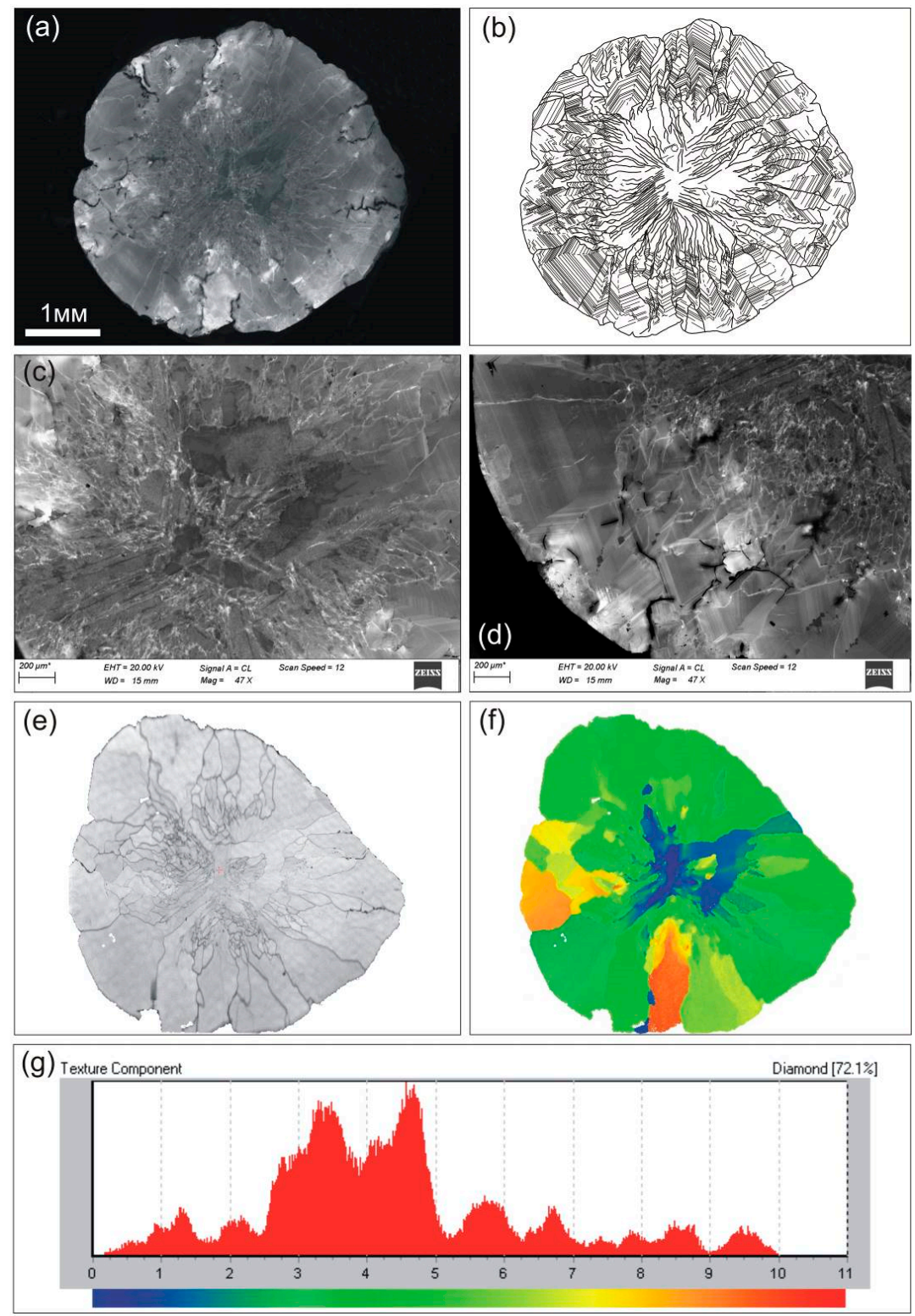

Figure 9. Central plate of the Brazilian ballas: (a) CL image; (b) Sector zoning scheme; (c,d) Details of the CL image; (e) Reflected light; (f) EBSD image; (g) Texture component diagram. 
The cubic diamond core is composed of fibrous fragments and regularly oriented crystal plates (Figure 9c). The plates are parallel to each other and have developed along the (110) planes of the crystal, indicating the growth of diamond in the direction of the cube edges. Peculiar skeletal formations composed of crystalline plates, crossing a cubic macrozone saturated with solid micro inclusions, are transformed into subindividuals with octahedral zoning (Figure 9d).

A single-crystal, atoll-shaped quadrilateral with elongated vertices centres the plate cut from a Brazilian ballas (Figure 9e,f). Its orientation equals $0^{\circ}$ on the EBSD diagram (Figure 9f), which corresponds to the dark blue colour on the scale of orientation of texture components (Figure 9f,g).

The atoll-shaped single-crystal area is a cross-section of a skeletal cubic crystal in the form of an edge crystal $\langle 110\rangle$. In general, the aggregate of single-crystal bunches can be represented as a hexahedral crystal with a funnel-shaped structure of faces. Some of its edges reach the ballas surface (Figure 9a,e) but at the same time change their orientation by $2-4^{\circ}$ (Figure $9 \mathrm{f}, \mathrm{g}$ ). Crystallites inside and outside the atoll are equally misoriented by $3-7^{\circ}$. Crystallites enclosed between the edge bundles $\langle 110\rangle$ have more significant misorientation, reaching a deviation of $7-10^{\circ}$ at the periphery. The appearance of self-deformation defects was accompanied by geometric selection of octahedral crystallites at the growth stage. An increase in the number of crystallites confined between the edge bunches $\langle 110\rangle$ and close misorientation angles suggests that their mutual displacements occurred in the (110) directions due to wedging by adjacent crystal blocks.

\section{Discussion}

The morphology of the UR specimen corresponds to the description of the shape of the ballas from the Krasnovishersky region [3]. However, inside the usual radial-fibrous spherulite, most of the methods have revealed previously unknown structural features in the form of a complex polycrystalline core surrounded by radiating fibrous crystallites.

According to the classification of the shape and texture of polycrystalline aggregates proposed by I. Sunagawa [26], the shape of the UR in terms of its internal structure refers to the type of "spherulites formed on a polycrystalline aggregate of the same species". In describing the morphology of spherulites, Sunagawa refers to illustrations and terminology developed by D.P. Grigoriev [27], who noted that the crystal grains that constitute the basis for the growth of a radial-fibrous aggregate of any mineral must be misoriented from each other. According to our observations, the nucleation of the UR aggregate occurred on an intergrowth of competing, randomly oriented, octahedral subindividuals, and the seed for their nucleation was a set of several microscopic diamond fragments. Geometric selection among crystalline subindividuals occurred until the normal growth of fibrous crystallites replaced the tangential growth of the octahedron. The main generators of splitting were the surface of deltoid crystal blocks and the re-entrant angles among them; therefore, the crystallite fibres are not in a strict radial orientation. The aggregate of fibrous crystallites developed in large sheaf-like bundles composing an integral spherical radialfibrous spherulite. According to the EBSD results, the beginning of the growth of the fibrous aggregate was marked by a sharp misorientation of the crystalline fibres, which is characteristic of split crystals [27]. The deviation of the angular values noticeably increases with the growth of the aggregate of crystalline fibres and at the boundaries of adjacent sheaf-like bunches.

According to the structure of the studied ballas, the generation of autodeformation defects by a crystalline aggregate, and then the growth of fibrous bunches was accompanied by active absorption of mechanical impurities. It is worth noting the unusual reverse nature of the change in the tangential growth of the polycrystalline core of the UR, consisting of octahedral subindividuals, by the mechanism of normal growth of the fibrous aggregate. The formation of spherulites is closely related to the splitting of crystals [28]. The main limiting conditions of this process are the achievement of a significant critical level of supersaturation for each substance in the crystal-forming medium and the presence of 
an impurity in it, which ensures the appearance of stresses when entering the crystal during growth.

Brazilian ballas is a split macrozonal diamond crystal of cubic habitus that consists of radiating, partially misoriented, detached crystallites. Detaching of the crystallites was initiated by the absorption of mechanical impurities from the environment, and further development of the crystallites, generated by the faces of the cubic core, was accompanied by a change of cubic with octahedral growth shape. The development of the detached subindividuals followed the geometrical selection typical of mutual growth of randomly oriented crystals on a flat substrate. Further crystal growth depended on the deviation from the radial direction angle. Thus, the crystals with smallest deviation from the radial orientation were in a most favourable position for further growth. Single crystals rays constituting the [100] edges of the skeletal cube and funnel-shaped concaved (100) faces filled with misoriented crystallites persevered in the split crystal. This crystallographic form is a skeletal variety of a rhombic dodecahedron $\langle 110\rangle$ [29].

A cubic crystal split is due to the appearance of stress among sectors and to the development of autodeformation along the boundaries of growth sectors of $<100>$ faces. An example of such parallel autodeformation was considered in the cubic diamond crystal of variety II [30]. The fibrous plates, oriented in (110) direction, were also observed in the $\langle 110\rangle$ growth sectors of the cubic diamond crystals of variety III [31]. It was suggested that their mutual shifts, related to the impurity defects, initiated splitting of the fibrous cubic crystals into spherical, pseudocubic crystals. Parallel shift translations along sectorial boundaries of a crystal are typical for the crystal growth at increased supersaturation and high concentration of the mechanical surface-active impurities in the crystallisation medium [32]. The aforementioned facts suggest that the split of the Brazilian ballas was initiated by the autodeformation defects and appeared in the ballas's cubic core, with intense absorption of mechanical impurities during the abrupt decrease of the supersaturation level. Geometrical selection at the growth stage of split octahedral crystals neutralised the effect of splitting and preserved the tetrahexahedron form of the crystal. Thus, we state that Brazilian ballas passed through volume dissolution at the final stage of its development. At the same time, the ballas's structure differs from that of the "Brazilian" and "Urals" types of globular diamonds.

The ballases and ballas-like diamonds of Yakutia have a pronounced individuality, especially well manifested in their internal structure. However, they have a common feature: all diamonds have a spherical shape, a single centre of growth, and a radial type of internal structure.

Yakutia spherical diamond RB-2 is an example of ballas-like outlook. These crystals were described as spherical curved facet dodecahedroids with curved instead of edge shapes and classified as ballases in Orlov's early classification of diamonds [33].

The zonal structure of ballas-like diamond crystal RB-2 demonstrates evidence of a change in the tangential layer growth of flat-faced octahedra by the dislocation growth of faces of octahedra. Absorption of the mechanical impurities by the octahedral face provoked the change of the crystal growth mechanism, which led to the dissymmetrisation of the crystal. Hemihedria of the simple forms manifest in the lowering of the diamonds' structurally determined hexahedral symmetry $m \overline{3} m$ to tetrahedral symmetry $\overline{4} 3 \mathrm{~m}$. According to the crystal zoning (Figure 4), the large faces of octahedra are observed on the surface of the octahedral core of the diamond revealed by dissolution, while smaller triangular faces are on the surface of the outer defect zone of the crystal. The presence of trigonal and tetragonal pits on the diamond surface is unambiguously interpreted as a dissolution process [34]. We conclude that positive and negative tetrahedral forms, related to the peculiarities of the crystal's structure and its anisotropy, appear on the surface of the spherical diamond crystal during dissolution. Crystal dissymetrisation accompanied the complication of the faceting. The morphology of the considered crystal displays "complication" of the (111) form of diamonds habitus (Figure 6c): (211), (311), (411), (100) faces of the [011] zone appear between adjacent octahedral (111) faces. These series of faces 
were observed earlier in the experiments on dissolution of spherical crystals [35] and were termed as "edges of dissolution". An appearance of the low indices faces on the curved crystal surface and edges during dissolution was observed. Protruding edges can be smoothed and consist of an arbitrary set of planes or can be hebetated by the separated faces. The origin of these forms due to dissolution is confirmed by the presence of negative trigons and by the presence of curved faces of the dodecahedroid. Therefore, influence of growth-related autodeformation in the peripheral zone of a diamond plays a decisive role in the formation of unusual hemihedral dissolution shapes.

A detailed study of the Yakutia ballases RB-4 and RB-5 found that they simultaneously exhibit signs of splitting and twinning. In general, they are partially split twin intergrowths of crystals that originated from one growth centre. It was found that the misorientation of crystallites is both random and regular in the radially fibrous fragments of the ballases. Cyclic and polysynthetic twinning of crystallites and their combinations play a leading role in the structure of the Yakutia ballases. In RB-4 and RB-5, twin intergrowths constitute the frame of a radial fibrous aggregate. The similarity in the structure of the Yakutia ballases and of the classical ballases is obvious, which enables classification of radiating aggregates as classical ballases.

Alluvial placers in the northeastern Siberian platform in Yakutia contain diamonds of variety VII, with signs of radial splitting [15,18]. A radial mosaic structure was found in polycrystalline diamond aggregates with signs of geometric selection from the Zarnitsa pipe in Yakutia [16,17]. The authors emphasised mutual similarity, genetic closeness of growth conditions, and similarity of morphology with ballases. However, in contrast to the Yakutia ballases studied in this work, twin intergrowths were not reported.

The formation of all ballas and ballas-like diamonds studied in this work was completed by the dissolution process. The stage of dissolution had a significant effect on the appearance of a spherical shape for both radially fibrous ballas spherulites and split spherocrystals and complex twinned aggregates. The deep dissolution process was comprehensive and affected most diamonds in the placers of the northeastern Siberian platform, which passed the final stage of dissolution in a hydrous carbonate-silicate melt [36]. The typical forms of diamonds dissolution bodies are rounded dodecahedroid or tetrahexahedroid depending on the initial shape of the crystals [37]. Radial intergrowths of split crystallites, large crystalline segregations, and twinning elements in an aggregate usually manifest in the formation of morphological features of the surface of dissolution of ballases. It is noted that the dissolution rate of various crystal faces is not sensitive to small misorientations of its crystal blocks [38]; therefore, the geometrical forms of dissolution of single crystals and split crystals can be identical.

\subsection{Crystallographic Model of Crystals Multiple Twinning in Ballases}

The phenomenon of twinning in the formation of varieties of ballas and ballas-like diamonds has an essential role. Twin intergrowths on the surface of a sample of Brazilian ballas were first described by A. Fersman and V. Goldshmidt [4]. Goniometric measurements showed that the sample was a complex polysynthetic twin, with some individuals showing signs of cyclic twinning. Morphological studies of the Urals ballases [2] established that their constituent grains are cyclic twin intergrowths; they form regular intergrowths around one common axis [011], and at one of its outputs, there is an open three-, four-, or five-sided relief figure bounded by the edges of the octahedra and twin seams among them.

Signs of multiple twinning were found in polished thin sections made from ballases synthesised from graphite [23]. The authors emphasised that the twinning planes (111) are radially oriented and can be traced from the centre of growth of the ballas to its surface. In this case, the growth of radially twinned crystallites proceeded from the centre of the ballas without the formation of a crystalline core and ended with the formation of twinned microcrystals. There are other examples of multiple twin intergrowths as well as cyclic and polysynthetic twins on the surfaces of natural and synthetic ballases $[13,14,19]$. 
There is a report on the findings of microscopic, ballas-like, polycrystalline intergrowths in the form of spherulites with five-pointed frames on the surface in the Sytykanskaya and Yubileinaya pipes [10]. The authors associated their morphology with the parallel intergrowth of several cyclic "spinel fives". Such a structure may indicate the radial orientation of a set of twin boundaries directed to the centre of growth that unite crystals into a regular aggregate.

Ch.B. Slawson first identified the fundamental possibility of multiple twinning of diamonds [39]; this type of twinning, characteristic for crystals of minerals of a cubic system, leads to the formation of various aggregate-like intergrowths. The author emphasised that diamond twins, consisting of more than three individuals, almost defy crystallographic analysis. Macroscopically, this is hampered by the absence of visual twin contact among numerous intergrown crystals. In addition, diamond lacks birefringence, which prevents the identification of twinned crystals in an aggregate by optical microscopy. Twins are identified by the difference in the hardness of individuals often observed on the ground surface of a diamond. Fersman and Goldshmidt were the first to discuss multiple twinning of diamond crystals [4]. A complex aggregate of crystals from South Africa, consisting of seven spinel twins that were also sequentially twinned with each other, was described [40]. Frequent twin intergrowths of diamonds from the Urals placers were reported [6], and the most complex of these consisted of 11 twinned octahedral crystals. However, usually complex twins of natural diamond consist of several crystals of different sizes. In consideration of the probable overgrowth of the twinned crystal by larger individuals, it is not possible to recognise such a regular intergrowth.

In the present study, twinning was identified by direct observation of twin seams on the surface along the boundaries of regular intergrowths (Figures 4-7). An example of multiple cyclic and polysynthetic twinning manifested at the end face of a crystal ray in the RB-5 ballas (Figure 10a); the cathodoluminescence of its radial section demonstrates polysynthetic twinning in the form of numerous parallel translations of crystalline blocks that cross the growth zoning of the aggregate (Figure 10c). Twinning patterns were found in the depth of the etching channels, corroding boundaries of twinned blocks exposed by late dissolution of the RB-5 ballas surface (Figure 10b). The walls and the bottom of the etching channels are decorated with dissolution figures that demonstrate the mirror symmetry of the relief elements (Figure 10b). They divide the rounded surface of the diamond into twinned segments, which indicates multiple twinning in the radial direction. Twin seams on the surface of RB- 5 ballas are visible in the CL image of the cut along the mirror symmetry of the elements of the deformed zoning of the aggregate (Figure 10d). EBSD of a polished cut of RB-4 revealed the symmetrical orientation of twinned crystal blocks (Figure 6).

Let us consider the models of the structure of ballas spherulites entirely consisting of twinned radial intergrowths of octahedral individuals. In a real structural model of crystal twinning, "intergrowth twins" are excluded, and only contact twins without gaps of the crystal structure exist. The remainder of the boundaries among individuals in a multiple twin intergrowth that do not have twin contacts are seams or voids filled with inclusions. It is this structure that we observed in our samples of Yakutia ballases with macroscopic signs of surface twinning.

The idealised geometric model of multiple twinning, according to the Spinel Law, can be visualised by adding new components to the twin intergrowth suggested by $\mathrm{Ch}$. Slawson [39], who provided an example of cyclic twinning along (111), which is widespread in diamonds, in the form of germination of three octahedral individuals (Figure 11a). 

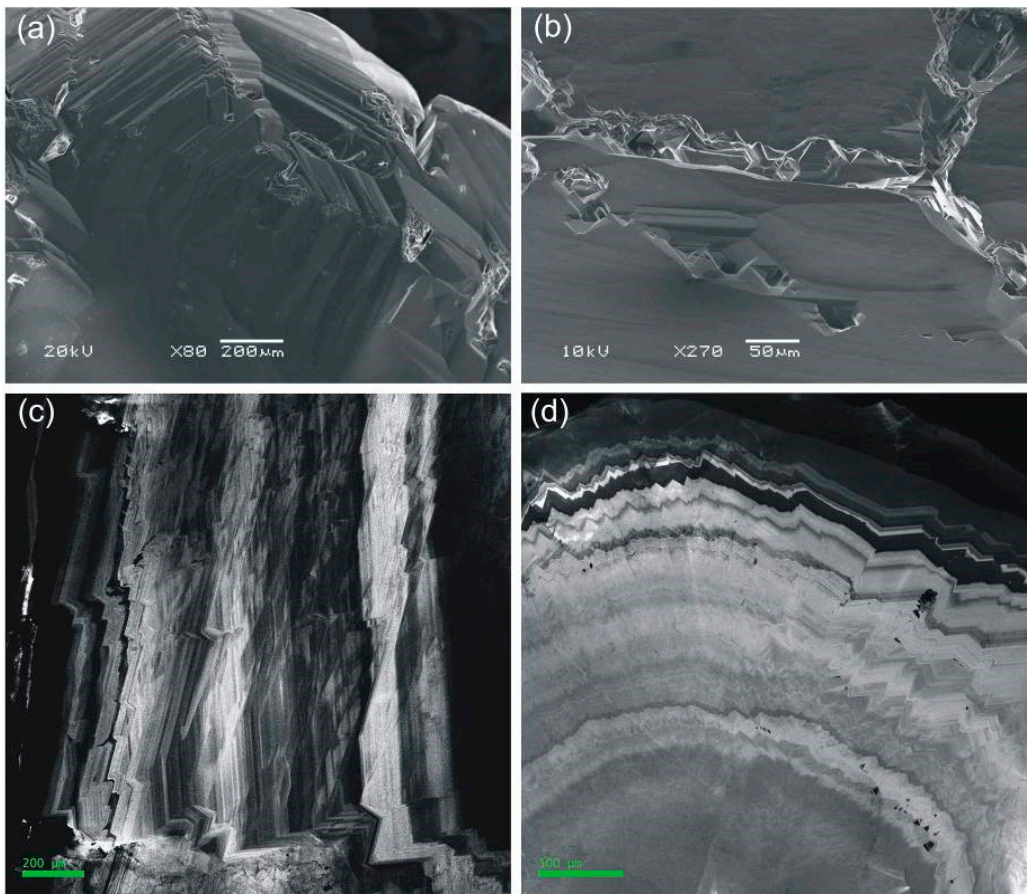

Figure 10. Evidences of twinning on the surface and in internal structure of the ballas-like diamonds of Yakutia: (a) Multiple twinning of the radial crystal ray on the RB-5 ballas surface (BSE); (b) Etching channels between twinned crystal blocks of RB-4 ballas (SEM); (c) Evidences of the polysynthetic twinning (CL) in the section of the ballas shown in Figure 10a; (d) Deformed zoning of the ballas (CL) under the etching channel shown in Figure 10b.
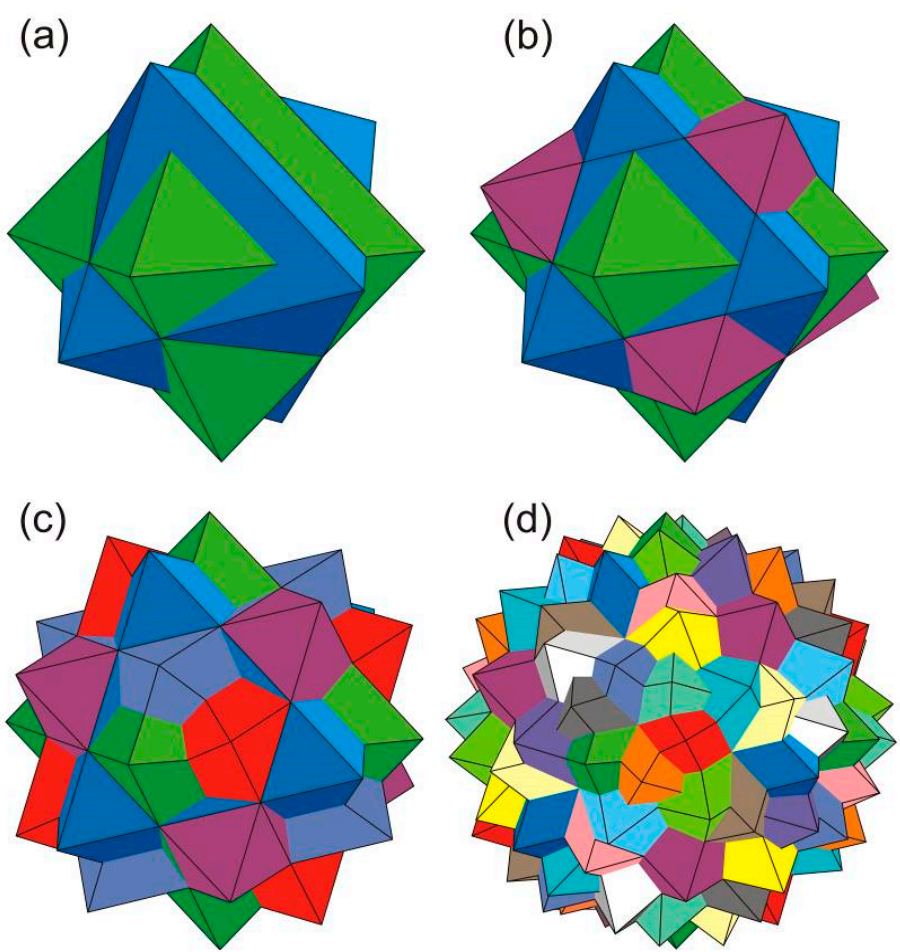

Figure 11. Geometric models of diamond octahedra multiple twinning on (111): (a) Model of the real twin intergrowth of the octahedral diamond crystals by Slauson [39]); (b) Three crystals Slauson's model; (c) Model of five twin crystals; (d) Idealized 16 crystals twin model, exhaustive geometrical possibilities of twinning of adjacent crystals. 
The third individual between the dominant extreme "blue" and "green" individuals in Slawson's figure was not shown. In this case, the plane of twinning of the two extreme crystals in the intergrowth is the plane (114) with respect to which they are symmetric. We have added one more twinned octahedron of violet colour to Slawson's figure (Figure 11b), and we conducted further geometric modelling of multiple twinning of octahedral crystals of this type of intergrowth. Twinning planes (111), (111), (1 $\overline{1} 1),(\overline{11} 1)$ served as twinning generators. A more complex multiple twin intergrowth supplemented by the fourth and fifth twinned individuals is shown on Figure 11c. Geometrically it already resembles spherulite. This aggregate has a crystallographic shape with external symmetry $m \overline{3} m$. Figure 11d shows the multiple twinning model, in which imaginary twin planes of the second order (114) connecting two extreme individuals in a three-component twin served as generators. The model consists of 16 octahedral components linked by the $m \overline{3} m$ symmetry and exhausts the geometric possibilities of twinning in the (111) and (114) planes. Slawson mathematically demonstrated further multiple twinning of higher orders; in geometrical interpretation, this leads to the formation of "intergrowths" of crystals, in which it is almost impossible to recognise regular intergrowths. These radiating bunches of crystals resemble spherulite, and the occurrence of such multiple twinned structures is unlikely because the primary twin surfaces will be completely hidden under the layers of new twin components. Similar geometric models of multiple intergrowth twins were used to explain the mechanism of the formation of diamond nodules grown by the CVD method [41]. The scheme of their formation is strongly indicative and can be applied to the genesis of the concentric layered structure of the hail-shaped diamond bort.

As noted above, numerous fragments, consisting of three- and five-component cyclic twins, were observed on the surface of ballases bearing traces of twinning. These twins' mutual relationship is difficult to interpret, and the problem of crystallographic study of the aggregate of twin complexes emerging at the surface of ballases has not yet been posed. Mutual twin intergrowths can exist between fragments of symmetric cyclic twins, and the presented three-dimensional models can explain their probable relations.

Pseudopentagonal and icosahedral intergrowths of cyclic spinel twins of cuboctahedral microcrystals of CVD diamond were found at the microlevel [42-44]. They can also be the prototype for the formation of complex multiple twins in ballases. At the same time, as was established in microdiamonds [45], growth dislocations can compensate for the angle of mismatch among five successive twins.

The symmetry of the ballas surface is quite predictable. Apart from the expected symmetric shapes of ballases formed by the mechanism of crystal splitting, a significant variety of symmetric shapes can be assumed for split multiple twinned ballas-like diamonds. In addition to the hexoctahedral $m \overline{3} m$ symmetry, these diamonds can have icosahedral symmetry.

\subsection{Crystal-Genetic Classification of Ballas and Ballas-Like Diamonds}

Diamond formation by sheaf-like splitting of a crystal in opposite directions into the bifoliate crystal [46] is an impossible principle because of the isometric form of the diamond crystals.

Early studies denied the radial-fibrous nature of ballas diamonds [47]; it was noted that ballas diamonds each have a crystalline (single crystal or crystals intergrowth) core with a polycrystalline coat [2]. Prior to the publication of diamond classification [48], ballas diamonds were mixed with the hail-like borts. A detailed study [13] demonstrated that the aggregate of radial oriented micro-diamonds on the notched surface is the only diagnostic sign of the ballas-like diamonds. Some scientists believe that ballas diamonds result from the overgrowth of the core crystal [49].

The hypothesis of the origin of ballas diamonds from carbonado [22] was not confirmed in our work.

Analysis of the literature data shows that morphology of many ballas diamonds deviates significantly from the typical ballas diamond forms. Thus, ballas diamonds 
from Prisayanie with radial-fibrous structures do not have spherical shapes [7]; instead, they were described as "lumpy diamonds" [50] and, later, were classified as "shapeless ballases" [8].

Most of the ballas diamonds attained a spherical shape after the growth process because of the dissolution of the surface $[2,3,11,13]$. The morphology of the growth surface of ballas diamonds was studied on the example of synthesised diamonds [13,14], which consists of crystals faceted with (111) and (100) faces on top of radial crystallites. It was noted that, in both natural and synthetic ballases, the $\mathrm{L}_{3}$ axes of crystallites are oriented towards the surface, and the crystals' growth plane is the face of an octahedron [13]. Synthesis via the CVD method resulted in ballas diamonds with preferred orientation of crystallites in (111) and (100) directions [19,51]. The crystallites of ballases often form cyclic and polysynthetic twins. Sometimes, ballases comprise solely twinned crystallites, and all the twin planes are radially oriented $[13,23,51]$.

Prior to the development of the classification features of the morphology of natural ballas diamonds, it is worth noting that aggregates of spherical crystals were often considered as ballas. Thus, many ballas diamonds of Brazil (Bahia), South Africa (Premier Mine) [2,34], and Yakutia (Russia) [9] display cubic, octahedral, or rhombic dodecahedral forms. These diamonds are probably split crystals that preserved the habitus growth form, just as the Brazilian ballas diamond with the form of split tetrahexahedron that we studied exhibited. Diamond spherocrystals also have well-developed shapes of curved facets dodecahedra and hexahedra [11,12]. However, the spherocrystals differ dramatically from the Brazil diamond studied in this work due to the smaller size of fibres (up to the first hundred microns) and significant misorientation of fibres $\left(>10^{\circ}\right)$.

It was emphasised in [11] that a strict distinction cannot be made between single crystals and polycrystalline aggregates of diamonds because there are many transitional forms between these two categories. A similar view was expressed regarding the similarity of ballas diamonds with crystal core and coated diamonds [10].

According to [3], ballas diamonds are transitional forms between crystals and aggregates with distinctly granular structures. Thus, ballas diamonds were placed between these two classes into variety VI. Following Orlov, we suggest retention of the conventional term "ballas-like diamonds" for the diamonds with radial structures and spherical shapes.

To build a crystal-genetic classification of ballas and ballas-like diamonds, it is necessary to complete a list of known morphological varieties with a set of new varieties described in this work. The updated list of morphological varieties of the ballas and ballas-like diamonds is as follows:

Classic ballas diamonds - coreless radial-fibrous spherulites of diamonds, usually with an ideal spherical shape. This type of ballas diamond has all the features of variety VI according to Orlov's [3] aggregates of diamonds;

Ballas diamonds with a polycrystalline core-radial-fibrous intergrowths of crystallites on the core of misoriented diamonds microcrystals that provided polycentric growth of the aggregate. The Urals sample reported in this work is an example of this new morphological variety;

Ballas-like spherocrystals - sectorial spherocrystals with radial orientation of fibres in the directions (100), (111), and (110);

Ballas-like hail-shaped aggregates-hail-shaped bort (South Africa) that is often considered "ballas diamonds" [49]. These aggregates have a core (either single crystal or polycrystalline) and a concentric zonal coat consisting of misoriented crystallites [14]. The genesis of this poorly studied form of aggregates remains unknown;

Ballas-like split crystals-these crystals appear as a result of auto-deformation caused by the absorption of mechanical impurities and abrupt change of normal crystal growth to tangential growth, which together cause the appearance of a multiple misoriented crystallites. The segregation of crystallites in the Brazil diamond resulted in the change of growth form from fibrous cuboid to facet octahedron; 
Ballas-like radial twin crystals - a new variety of the ballas-like intergrowth with growth planes twinning radiated from the centre. These aggregates emerged in a process of multiple cyclic, polysynthetic, and complex twinning of diamond crystals;

Ballas-like globular crystals - a new form of hemihedric globular crystals. The hemihedria of the diamond shape is caused by auto-deformation defects that appear during the growth of euhedral crystals in the conditions of unusual reverse change of tangential crystal growth, with polycentre crystal growth accompanying selective sorption of micro-impurities in the conditions of low supersaturation. The spherical shape of globular crystals is a result of a dissolution process.

The next step is to determine basic and mixed morphological varieties of ballas and ballas-like diamonds. Some of these diamonds (e.g., split and radiating twin crystals) were observed in the ballas diamonds of Yakutia.

\subsection{Crystal Genetic Scheme of Ballas and Ballas-Like Diamonds}

The zonal character of the crystallographic forms of the studied ballas-like diamonds allows for tracking of the trends in the evolution of the ballas morphology and for placing these diamonds in a certain position in the conventional crystal-genetic scheme that links the mechanism of crystal growth and crystal forms with the supersaturation of carbon [26,52]. Figure 12 displays the characteristic forms of diamond morphological varieties with an indication of the corresponding crystal growth mechanism ordered according to the level of supersaturation: polynuclear dislocation growth of octahedral crystal; twodimensional tangential growth of octahedral crystal; and normal crystal growth of fibrous cuboids, fibrous spherocrystals, and radiate-fibrous ballas diamonds. The morphological varieties of ballas and ballas-like diamonds are ordered according to the level of supersaturation and the presence of the defect-forming impurities in the crystal growth media, and analysis of the evolution of crystal morphology shows that the ballas-like diamonds form at the drop of the supersaturation, with a change from one crystal growth mechanism to another. The morphology of ballas and ballas-like diamonds reveals the history of the changes of the level of supersaturation.

A classical spherical ballas in the form of radial-fibrous aggregate and sectorial spherocrystals of dodecahedron and tetrahexahedron shapes, with the radial and parallel orientation of the fibres in the directions (100), (111), and (110), occurs in the region of extreme supersaturation (Figure 12).

The origin of the Brazilian ballas-like split crystal occurs in the region of high supersaturation. The nucleus of the crystal (a fibrous cuboid) is covered with misoriented, zonal, octahedral crystallites passed through geometric selection. The high speed of diamond growth accompanied with the intensive absorption of mechanical impurities and sharp decrease of the level of supersaturation caused the appearance of defects, separation, and misorientation of the crystallites. A shift from normal crystal growth to the tangential one leads to the change of cubic to octahedral crystal shape.

Unlike the Brazilian ballas-like diamond, the growth of the Urals ballas diamond occurs in conditions of increasing supersaturation. Such an unusual sharp reverse of supersaturation explains the rarity of finding such diamonds in nature. The increase of the supersaturation manifests in the change of faceted octahedral zoning in the polycrystal nucleus of the ballas via the fibrous growth of the radially oriented crystallites. According to our observation, the change of tangential growth with the normal one occurred without interruption of the crystallisation process. 


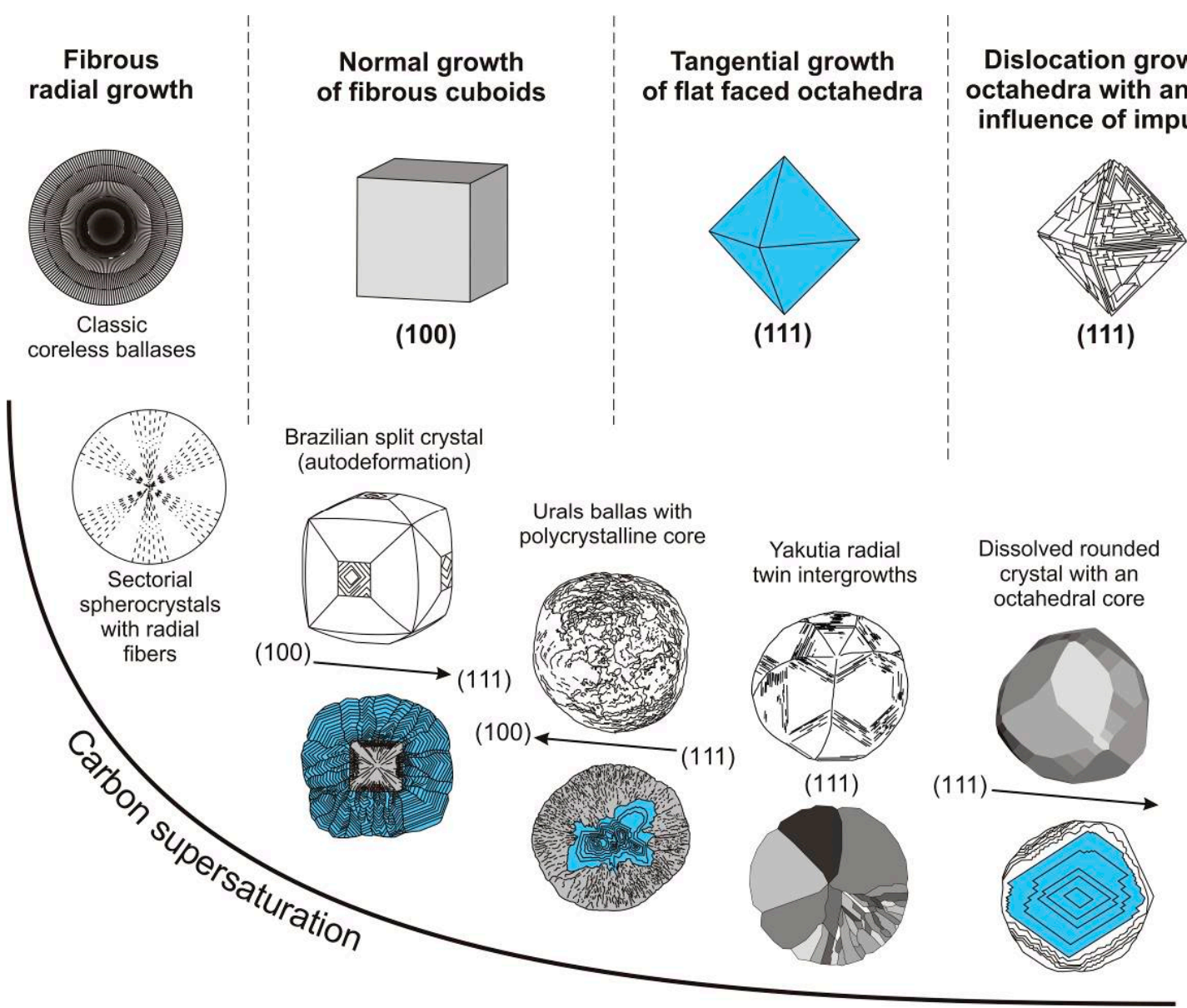

Figure 12. Crystal genetic scheme of ballas and ballas-like diamonds imposed on the Sunagawa diagram of the morphological type vs supersaturation, considering the influence of impurities in the crystallization medium.

Nucleation and growth of the complex spherulites that consist of split and radial multiple twinned crystallites probably occurred at higher supersaturation values than those that are typical for the growth of the flat-face octahedra. High supersaturation is a basic condition for the formation of autodeformation defects such as crystal splitting, twinning, and deformation [32].

A decrease of supersaturation (supercooling) leads to the following sequence of crystal formation: spherulites $>$ sheaf-like aggregate $>$ contact and penetration twins $>$ single crystals [53]. Therefore, the position of ballas diamonds with multiple radial twin crystals on a crystal-genetic scheme is between the area of normal crystal growth and the area of tangential growth of octahedral crystals (Figure 12).

A decrease of supersaturation from moderate (tangential crystal growth) to low (dislocation growth) values leads to the change from flat-face crystal shape to the polycentric octahedral crystal with lowered tetrahedral external symmetry. The appearance of hemihedral forms of diamonds is probably due to the selective adsorption and trapping of the impurities, which breaks the speed of growth of some faces of octahedral crystals at the decrease of the carbon supersaturation and level of diffusion in the crystallisation medium. This crystal is an end-member of the crystal-morphological series of ballas-like spherical crystals of diamonds, which covers the gamut of supersaturation levels in the diamond-forming medium.

Most natural ballas and ballas-like diamonds with curved dissolution faces obtained their final spherical shapes by resorption $[2,6,11,13,33]$ probably in the water-containing melt; this is confirmed by the fact that, at present, all known ballas diamonds have been found only in the placers in Brazil, South Africa, the Urals, and Yakutia, in association with 
diamonds of curved face dodecahedra and cuboids that passed through intensive bulk dissolution [36,37].

\section{Conclusions}

The presented study yields new morphologic varieties of ballas and ballas-like diamonds: Urals ballas that originated from polycrystalline core, Brazilian ballas-like split cuboids, Yakutia ballas-like complex radial twin aggregates, and Yakutia ballas-like crystal with signs of hemihedral symmetry. The formation of the ballas-like form of the studied diamonds was caused by an abrupt change of the supersaturation that changes the crystal growth mechanism. We constructed the crystal-genetic classification of ballas-like diamonds on the basis of the analysis of the morphology and inner structure of ballas-like diamonds with the framework of modern models of formation of the radial aggregates, growth defects, and radial twin aggregates. Our new crystal-genetic model of ballas and ballas-like crystals growth fits well the Sunagawa model that links the supersaturation with the crystal growth mechanism. The observed morphological series of the ballas-like diamonds "spherulite $>$ split crystal $>$ radial twin aggregate $>$ single crystal" correlates with the level of supersaturation of carbon in the crystal-forming environment.

The present study's results solve the problem with the identification of the morphological features of ballas diamonds and provide classification for ballas-like crystals and aggregates of diamonds as separate morphological varieties in the general crystalgenetic classification.

Author Contributions: Conceptualization and methodology, A.P. and D.Z; software, visualization A.P.; investigation, stadied samples by optical and scanning electron microscopy, A.P., D.Z., E.V.; performed the electron backscatter diffraction experiments, K.K.; writing —original draft preparation, A.P.; project administration, D.Z. All authors have read and agreed to the published version of the manuscript.

Funding: This research was supported by Russian Science Foundation (project No. 16-17-10067).

Conflicts of Interest: The authors declare no conflict of interest.

\section{References}

1. Williams, A.F. The Genesis of Diamond; E. Benn Ltd.: London, UK, 1932; Volume 2, p. 636.

2. Orlov, Y.L. Diamond Morphology; Izd. AN SSSR: Moscow, Russia, 1963; p. 233. (In Russian)

3. Orlov, Y.L. The Mineralogy of Diamond; John Wiley: New York, NY, USA, 1977; p. 233.

4. Fersman, A.E.; Goldschmidt, V. Der Diamant: Eine Studie. C; Winter's: Heidelberg, Germany, 1911; p. 274.

5. Trueb, L.F.; Barrett, C.S. Microstructural Investigation of Ballas Diamond. Am. Mineral. 1972, 57, $1664-1680$.

6. Kukharenko, A.A. Diamonds of the Urals; Gosgeoltekhizdat: Moskow, Russia, 1955; p. 512. (In Russian)

7. Kaminsky, F.V.; Kirikilitsa, S.I.; Polkanov, Y.A.; Khrenov, A.Y.; Malogolovets, V.G.; Nachalnaya, T.A.; Podzyarei, G.A. Ballas Prisayanya. Dokl. Akad. Nauk SSSR 1982, 267, 1218-1221. (In Russian)

8. Kaminsky, F.V.; Klyuyev, Y.A.; Prokopchuk, B.I.; Shcheka, S.A.; Smirnov, V.I.; Ivanovskaya, P.N. The First Carbonado Finds and the New Ballas Find in the Soviet Union. Dokl. Akad. Nauk SSSR 1978, 242, 687-689. (In Russian)

9. Afanasiev, V.P.; Yefimova, E.S.; Zinchuk, N.N.; Koptil, V.I. Atlas of Morphology of Diamonds from Russian Sources; SPC UIGGM, SB RAS: Novosibirsk, Russia, 2000; p. 298.

10. Bartoshinsky, Z.V.; Kvasnytsya, V.N. Crystallomorphology of a Diamond from Kimberlite; Naukova Dumka: Kiev, Ukraine, 1991; p. 172. (In Russian)

11. Martovitsky, V.P.; Bul'enkov, N.A.; Solodova, Y.P. Features of the internal structure of crystal-like Ballas. Izv. Akad. Nauk SSSR Ser. Geol. 1985, 6, 71-77. (In Russian)

12. Orlov, Y.L.; Bulienkov, N.A.; Martovitsky, V.P. Spherical diamond crystals: A new type of natural fibrous single crystals. Dokl. Akad. Nauk SSSR 1980, 252, 703-707. (In Russian)

13. Nikol'skaya, I.V.; Vereshchagin, L.F.; Orlov, Y.L.; Feklichev, Y.M.; Kalashnikov, Y.A. Comparative Study of Natural and Synthesized Ballases. Dokl. Akad. Nauk SSSR 1968, 182, 77-79. (In Russian)

14. Lux, B.; Haubner, R.; Holzef, H.; DeVrie, R.C. Natural and Synthetic Polycrystalline Diamond, with Emphasis on Ballas. Intern. J. Refract. Met. Hard Mater. 1997, 15, 263-288. [CrossRef]

15. Ragozin, A.L.; Zedgenizov, D.A.; Kuper, K.E.; Shatsky, V.S. Radial mosaic internal structure of rounded diamond crystals from alluvial placers of Siberian Platform. Mineral. Petrol. 2016, 110, 861-875. [CrossRef] 
16. Ragozin, A.L.; Zedgenizov, D.A.; Shatsky, V.S.; Kuper, K.E. Formation of mosaic diamonds from the Zarnitsa kimberlite. Russ. Geol. Geophys. 2018, 59, 486-498. [CrossRef]

17. Ragozin, A.L.; Zedgenizov, D.A.; Kuper, K.E.; Pal'yanov, Y.N. Specific Internal Structure of Diamonds from Zarnitsa Kimberlite Pipe. Crystals 2017, 7, 133. [CrossRef]

18. Shiryaev, A.A.; Khokhryakov, A.F.; Reutsky, V.N.; Golovanova, T.I. Structure and Defects in Natural Ballas-Type Diamonds: A Case Study. Geochem. Int. 2020, 58, 1299-1312. [CrossRef]

19. Haubner, R.; Lux, B. Deposition of ballas diamond and nano-crystalline diamond International. J. Refract. Met. Hard Mater. 2002, 20, 93-100. [CrossRef]

20. Belyankina, A.V.; Sozin, Y.I.; Cherepenina, E.S.; Butakova, T.Y. On the structure of polycrystalline diamonds of the Ballas and Carbonado type. Synth. Diam. 1976, 2, 13-17. (In Russian)

21. Apollonov, V.N.; Borovikov, N.F.; Vereshchagin, L.F.; Kalashnikov, Y.A.; Shalimov, M.D. Structure of Diamond Dendrites of Synthetic Ballases. Dokl. Akad. Nauk SSSR 1976, 226, 558-559.

22. Moriyoshi, Y.; Kamo, M.; Setaka, N.; Sato, Y. The microstructure of natural polycrystal diamond, carbonado and ballas. J. Mater. Sci. 1983, 18, 217-224. [CrossRef]

23. Vereshchagin, L.F.; Apollonov, V.N.; Shalimov, M.D.; Kalashnikov, Y.A.; Grigoriev, V.M. About Diamond Twins of Synthetic Ballases. Dokl. Akad. Nauk SSSR 1973, 208, 844-845.

24. Bühlmann, S.; Blank, E.; Haubner, R.; Lux, B. Characterization of ballas diamond depositions. Diam. Relat. Mater. 1999, 8, 194-201. [CrossRef]

25. Kuper, K.E.; Zedgenizov, D.A.; Ragozin, A.L.; Shatsky, V.S. X-ray topography of natural diamonds on the VEPP-3 SR beam. Nucl. Insrum. Meth. A 2009, 603, 170-173. [CrossRef]

26. Sunagawa, I. Crystals: Growth, Morphology and Perfection; Cambridge University Press: Cambridge, UK, $2005 ;$ p. 295.

27. Grigoriev, D.P. On the Genesis of Minerals. Proc. Russ. Miner. Soc. 1947, 76, 51-62. (In Russian)

28. Punin, Y.O. Splitting of crystals. Proceed. Russ. Miner. Soc. 1981, 6, 666-686. (In Russian)

29. Shafranovsky, I.I. Mineral Crystals: Curved, Skeletal and Granular Forms; Gosgeoltekhizdat: Moscow, Russia, $1961 ;$ p. 332. (In Russian)

30. Pavlushin, A.D.; Zedgenizov, D.A.; Pirogovskaya, K.L. Crystal Morphological Evolution of Growth and Dissolution of CurveFaced Cubic Diamonds from Placers of the Anabar Diamondiferous Region. Geochem. Int. 2017, 55, 1153-1163. [CrossRef]

31. Orlov, Y.L.; Bulienkov, N.A.; Martovitsky, V.P. A Study of the Internal Structure of Variety III Diamonds by X-Ray Section Topography. Phys. Chem. Miner. 1982, 8, 105-111. [CrossRef]

32. Punin, Y.O. Role of the habit of crystals in formation of autodistorsion defects. Proceed. Russ. Miner. Soc. 2000, 6, 1-11. (In Russian)

33. Orlov, Y.L. Varieties of crystals and polycrystalline diamond splices. In New Data on Minerals of the USSR; Nauka: Moscow, Russia, 1965; Volume 16, pp. 141-154. (In Russian)

34. Fedortchouk, Y.; Canil, D. Diamond oxidation at atmospheric pressure: Development of surface features and the effect of oxygen fugacity. Eur. J. Mineral. 2009, 21, 623-635. [CrossRef]

35. Mokievsky, V.A. Morphology of crystals. In Methodological Guid; Nedra: Leningrad, Russia, 1983; p. 296. (In Russian)

36. Zinchuk, N.N.; Koptil, V.I. Typomorphism of Diamonds of the Siberian Platform; Nedra: Moscow, Russia, 2003; p. 603. (In Russian)

37. Khokhryakov, A.F.; Pal'yanov, Y.N. The evolution of diamond morphology in the process of dissolution: Experimental data. Am. Mineral. 2007, 92, 909-917. [CrossRef]

38. Heimann, R.B. Auflosung von Kristallen: Theorie und Technische Anwendung, Applied Mineralogy; Springer: New York, NY, USA, 1975; Volume 8, p. 270. (In German)

39. Slawson, C.B. Twinning in the Diamond. Am. Mineral. 1950, 35, 193-206.

40. Palache, C. Multiple Twins of Diamond and Sphalerite. Am. Mineral. 1932, 17, 360-361.

41. Tamor, M.A.; Everson, M.P. On the role of penetration twins in the morphological development of vapor-grown diamond films. J. Mater. Res. 1994, 9, 1839-1849. [CrossRef]

42. Hofmeister, H. Shape variations and anisotropic growth of multiply twinned nanoparticles. Zeitschrift fur Kristallographie 2009, 224, 528-538. [CrossRef]

43. Kvasnytsya, V.N.; Kvasnytsya, I.V. Cyclic Twins of CVD Diamond Crystal. J. Superhard Mater. 2019, 41, 369-376. [CrossRef]

44. Mani, R.C.; Sunkara, M.K. Kinetic faceting of multiply twinned diamond crystal during vapor phase syntesis. Diam. Relat. Mater. 2003, 12, 324-329. [CrossRef]

45. Son, S.I.; Chung, S.J. Multiply Twinning of Diamond Synthesized by Acetylene Flame. Zeitschrift fur Kristallographie 2004, 219, 494-505.

46. Lehmann, O. Die Neue Welt der Flüssigen Kristalle und Deren Bedeutung für Physik, Chemie, Technik und Biologie; Akademische Verlagsgesellschaft: Leipzig, Germany, 1911; Volume VI, p. 388. (In German)

47. Fischer, R.B. The 'Ballas' Form of Diamond. Nature 1961, 189, 50. [CrossRef]

48. Palache, C.; Berman, H.; Frondel, C. Dana's System of Mineralogy, 7th ed.; Wiley: New York, NY, USA, 1944; Volume 1, pp. 1-834.

49. DeVries, R.C.; Robertson, C. The Microstructure of Ballas (Polycrystalline Diamond) by Electrostatic Charging in the SEM. J. Mater. Sci. Lett. 1985, 4, 805-807. [CrossRef]

50. Dibrov, V.E.; Mironov, I.K.; Khol, F.I.; Andrianov, V.T. Geological Structure and Diamond Content of the South-Western Part of the Siberian Platform; Academy of Sciences: Moscow, Russia, 1960; p. 97. (In Russian) 
51. Joksch, M.; Wurzinger, P.; Pongratz, P.; Haubner, R.; Lux, B. Characterization of Diamond Coatings with Transmission Electron Microscopy. Diam. Relat. Mater. 1994, 3, 681-687. [CrossRef]

52. Sunagawa, I. Growth of Crystals in Nature. In Materials Science of the Earth's Interior; Terrapub: Tokyo, Japan, $1984 ;$ pp. $63-105$.

53. Kozlova, O.G.; Orlova, A.O. Formation of Spherulites. Dokl. Akad. Nauk SSSR 1985, 280, 628-630. (In Russian) 